\title{
Buying groceries in brick and click stores: category allocation decisions and the moderating effect of online buying experience
}

\author{
Katia Campo $^{1}$ \\ KU Leuven
}

Els Breugelmans

KU Leuven

Published as: K. Campo and E. Breugelmans (2015), "Buying Groceries in Brick and Click Stores: Category Allocation Decisions and The Moderating Effect of Online Buying Experience," Forthcoming in Journal of Interactive Marketing.

\footnotetext{
${ }^{1}$ Corresponding Author: Katia Campo is Professor of Marketing at KU Leuven, Faculty of Economics and Business. Address: Korte Nieuwstraat 33, 2000 Antwerp (Belgium). Tel. +3232011803. E-mail: katia.campo@kuleuven.be
}

Els Breugelmans is Associate Professor of Marketing at KU Leuven, Faculty of Economics and Business. Address: Korte Nieuwstraat 33, 2000 Antwerp (Belgium). Tel. +3232011882. E-mail: els.breugelmans@kuleuven.be 


\title{
Buying groceries in brick and click stores: category allocation decisions and the moderating effect of online buying experience
}

\begin{abstract}
The large majority of online grocery shoppers are multichannel shoppers, who keep visiting offline grocery stores to combine convenience advantages of online shopping with selfservice advantages of offline stores. An important retail management question, therefore, is how these consumers divide grocery purchases across the retailer's online and offline channel. We provide a comprehensive analysis of the impact of category characteristics on the allocation pattern of multichannel grocery shoppers, and find that category allocation decisions are not only affected by marketing mix differences between the online and offline channel, but also by intrinsic category characteristics like perceived purchase risk and shopping convenience. In addition, we examine the effect of online buying experience. In line with expectations, we find that it can affect allocation patterns in different ways: (i) it attenuates the perceived risk of buying sensory categories online, thereby reducing differences in online category share, (ii) it reinforces marketing mix (assortment) effects, thereby making online category share differences more pronounced, and (ii) it has no effect for factors such as promotions that are easy to evaluate without experience, thereby leaving the online category share stable. In addition to different experience effects across allocation factors, we also observe variations in experience effects across consumer segments.
\end{abstract}

Keywords: multichannel shopping; online grocery shopping; category allocation decision; buying experience 
While lagging behind in comparison with many other consumer markets, online shopping for groceries has increased dramatically over the last few years, and now tops the agenda of all major grocery retailers (Warschun 2012). "[Grocery] retailers are increasingly finding they must innovate in ways that make it easier and more convenient for their customers to get what they need without missing a beat, according to Nielsen's “Continuous Innovation” report, which found that convenience itself may be the most creative and energetic example of retail innovation" (Nielsen 2014). Of these convenience-oriented retail innovations, the shift towards multichannel offline-online retailing is one of the most important and successful practices. Several of the large grocery retail chains (such as Walmart, Tesco and Ahold) now operate an online store next to their offline supermarket outlets ('brick and click' grocery retailers). By increasing their service levels, multichannel retailers aim to retain existing customers and gain new customers in the increasingly competitive retail environment (Chintagunta et al. 2012; Kabadayi et al. 2007; Neslin and Shankar 2009; Zhang et al. 2010).

Customers clearly appreciate and take advantage of this extended service. The large majority of online grocery shoppers are multichannel shoppers who visit both the online and offline channel, thereby combining convenience advantages of online shopping with self-service advantages of offline stores (Alba et al. 1997; Chu et al. 2008; Chu et al. 2010; Konuş et al. 2008; Venkatesan et al. 2007). Although multichannel shoppers visit both channels, their purchase behavior tends to differ across the online and offline channel, both in the tendency to buy certain categories and in the sensitivity to marketing mix instruments. For instance, a product's online intangibility can result in low(er) online purchase shares, especially for sensory categories that consumers prefer to physically examine before purchasing them (Degeratu et al. 2000). Bulky and heavy categories, in contrast, tend to be top-selling categories in online stores, 
because of the high online shopping convenience benefits (Chintagunta et al. 2012). Prior research has also shown that households tend to be more brand loyal and size loyal, but less price sensitive in the online than in the offline channel (Chu et al. 2010). Because channel differences in assortment and price can vary across categories, this may also influence consumers' allocation patterns over the online and offline channel. As a result, the multichannel shopping context clearly adds to the complexity of retailers' management decisions, and multichannel grocery retailers need more insight into how shoppers allocate their purchases across their online and offline stores (cf. Dholakia et al. 2010; McPartlin and Dugal 2012; Shankar and Yadav 2010).

The purpose of this study is to improve the understanding of multichannel shopping behavior and to provide a better insight into the underlying mechanisms and factors that determine how multichannel shoppers allocate their category purchases across the online and offline channel. Building on the multiple store and online shopping literature, we analyze the impact on purchase allocation patterns at the category level, and take 'traditional' marketing mix based factors as well as 'intrinsic' category characteristics into account. Given that online grocery shopping is still in the 'innovation stage' (small, but rapidly increasing number of consumers who start buying groceries online), our model explicitly accounts for dynamic adjustments of allocation patterns as consumers gain more experience with buying groceries online. We also account for the possibility that managers adjust category assortment and pricing decisions to anticipated channel differences in buying behavior, and correct for potential endogeneity biases in marketing mix effects.

Our research provides important contributions to the marketing and retailing literature. First, we extend insights from the multiple store shopping literature by examining category allocation decisions in a substantially different multichannel retail context, with fundamental 
differences in the factors driving purchase allocation decisions. Second, we add to the multichannel literature by providing a comprehensive analysis of the factors that can cause differences in online purchase tendency across grocery categories. As indicated in previous (offline) purchase behavior studies (Hoyer and MacInnis 2010), grocery shopping differs substantially from other purchase contexts, as the same products are purchased repeatedly, purchase involvement tends to be low, and consumers are not prepared to spend much time and effort to search for the 'best' product. Findings of previous multichannel studies - which mainly focused on durable goods - are therefore not directly transferrable to, and provide little insight into what drives purchase allocation decisions in a multichannel grocery shopping context. The limited number of studies on multichannel purchases of groceries focused on specific issues, such as channel differences in sensitivity to specific marketing mix instruments (e.g., price sensitivity: Chu et al. 2008; Chu et al. 2010), the degree of brand exploration across both channels (Chu et al. 2010; Pozzi 2012) or the impact of transaction costs on channel choice (Chintagunta et al. 2012). While useful to develop expectations on the impact of specific factors, they do not provide insights into the overall purchase patterns of multichannel shoppers. Third, we refine and extend previous research on online buying experience effects (Ansari et al. 2008; Frambach et al. 2007; Kim et al. 2008), by examining experience effects on category level purchase decisions and by taking different possible effects of experience into account.

From a managerial point of view, our results help multichannel retailers to improve the mix of customer services and enhance their overall value proposition for multichannel shoppers (Zhang et al. 2010). Our results can guide online category management and promotional decisions of multichannel retailers to stimulate online purchases. Striving for larger online shopping baskets can be beneficial and generate additional revenue that may cover the high fixed 
costs that online retailers face (e.g., storing and delivery costs). Next, by obtaining a better insight into the effects of experience on different types of factors that influence consumers' category purchase allocation decisions, multichannel retailers can better assess the importance of stimulating trial and repeat purchases (to generate positive experience effects) vs. taking corrective actions (e.g., adjust channel differences in assortment and/or price).

\section{Conceptual Framework}

In this section, we provide a conceptual framework on how multichannel shoppers allocate category purchases across the online and offline channel operated by a single retailer. We take the overall allocation of grocery purchases across channels (channel choice and visit frequency) as given, and examine whether and how category-specific allocation factors lead to deviations from the overall allocation scheme (i.e., result in disproportionately low or high channel shares in category purchases). Building on the multiple store and multichannel shopping literature, we explain category allocation decisions as the outcome of a shopping utility maximization process that accounts for (i) acquisition utility, i.e., the benefits that consumers receive (e.g., product quality and promotions) and the costs they need to give up (e.g., price) when acquiring the product, and (ii) transaction utility, i.e., the benefits consumers receive (e.g., time-saving home delivery systems) and the cost they need to bear (e.g., perceived risk of online ordering) when transferring the products from the store to home (Baltas et al. 2010; Chintagunta et al. 2012; Gupta and Kim 2010; Vroegrijk et al. 2013). Below, we identify the major acquisition and transaction utility related factors and discuss how they are expected to influence category allocation patterns over the online and offline channel. Next, we discuss how online buying experience in the category plays a moderating role (see also Figure 1). 
[Insert Figure 1 about here]

\section{Acquisition utility: The impact of marketing mix instruments}

Studies on multiple store shopping behavior in an offline context have demonstrated that marketing mix based differences in acquisition utility - such as assortment and price differences - are important drivers of category allocation decisions across stores (Gijsbrechts et al. 2008; Vroegrijk et al. 2013). As explained in more detail below, even though online and offline stores that belong to the same chain have a similar price/quality positioning, marketing mix instruments can still differ across channels for several reasons (Neslin et al. 2006; Wolk and Ebling 2010). In the following, we discuss the impact of channel differences in assortment, price and promotion intensity (Fox and Hoch 2005) and examine the differential effect of in-store incentives aimed at stimulating unplanned purchases on allocation decisions (Breugelmans and Campo 2011).

Assortment Differences. Online and offline assortments can differ in size for several reasons. On the one hand, online stores provide the opportunity to carry a larger assortment as a result of the online store's limitless shelves. On the other hand, cost and demand constraints, and the need to respect very short delivery times, can be reasons to restrict online assortments for some categories (such as groceries). The literature on assortment effects suggests that larger assortments tend to be preferred over smaller ones because they offer more choice flexibility and enhance feelings of autonomy (Oppewal and Koelemeijer 2005; Sloot et al. 2006) ${ }^{2}$. We expect that channel differences in assortment size can influence channel allocation decisions, such that consumers are more inclined to buy the category in the channel that offers the largest assortment.

\footnotetext{
${ }^{2}$ While larger assortments may also come at the cost of more difficult evaluation processes because of information overload, choice conflict or regret (Dhar 1997; Huffman and Kahn 1998), the general expectation appears to be that the advantages of larger assortments tend to cancel out potential disadvantages (cf. negative effects of assortment reductions on category sales; Borle et al. 2005; Sloot et al. 2006).
} 
Price Differences. Multichannel retailers can charge different prices in their online and offline channel in view of cost and demand considerations (Neslin and Shankar 2009; Wolk and Ebling 2010). For one, the online channel may entail higher operational costs, including additional ICT, picking, handling and delivery costs. At the same time, the online channel may experience cost savings as the result of lower store layout, display and shelf replenishment costs, and because price adjustments can literally be executed by pressing a button. In addition, several studies provided evidence of channel differences in price sensitivity (Chu et al. 2008; Wolk and Ebling 2010). Multichannel grocery retailers can incorporate these cost and price sensitivity differences in product prices to safeguard profit margins (compensate for higher online operational costs) or to stimulate online purchases (let consumers benefit from lower online operational costs or use different price levels to exploit price sensitivity differences). Similar to assortment differences, we assume that multichannel shoppers will incorporate price differences in their category allocation decisions, and allocate a lower share of category purchases to the channel where the category is least attractive in price (cf. multiple store shopping literature; Gijsbrechts et al. 2008; Vroegrijk et al. 2013).

Promotion differences. The intensity of promotional actions can differ between the online and offline channel of the same retailer, to account for differences in price/promotion sensitivity across channels (Wolk and Ebling 2010), or for more pragmatic reasons such as different account managers being in charge of the promotion planning in each channel (Avery et al. 2012). Consumers can react by temporarily adjusting their allocation patterns to take advantage of more attractive promotional actions in one of both channels.

In-store stimuli. In-store stimuli may trigger a forgotten need or new idea. Compared to the offline channel, online shoppers tend to be less sensitive to these in-store stimuli for several 
reasons: they can more easily control their shopping route and immediately navigate to the needed category by clicking the category's page, they do not have to wait at fresh meat/fish counters or at the cash register (locations that are often used to store impulse products) and the more 'functional' online shopping environment can evoke a more goal-oriented shopping attitude, making consumers more reluctant to deviate from their purchase plans and give in to impulse purchases (Babin and Darden 1995). We therefore expect that the online store will obtain a lower share of purchases for impulse categories that consumers do not usually plan to buy in advance and for which they tend to be very sensitive towards in-store stimuli.

\section{Transaction utility: The impact of perceived purchase risk and shopping convenience}

Multichannel studies have indicated that channel differences in transaction costs can depend on the categories that need to be purchased and are mainly based on two components: (i) perceived purchase risk, and (ii) shopping convenience (Chintagunta et al. 2012; Gupta and Kim 2010). Online purchases can be associated with a higher perceived purchase risk as a result of the products' intangibility, i.e., the lack of sensory decision cues (Degeratu et al. 2000; Laroche et al. 2005). On the other hand, online shopping provides convenience advantages, through the possibility of having products picked up by online grocery staff and having them delivered at home (Chu et al. 2010; Gupta and Kim 2010).

Perceived purchase risk. The lack of sensory information in the online store can constitute an important disadvantage for sensory categories - such as fresh meat, vegetables and fruit - that tend to be evaluated prior to purchase based on sensory information cues (Degeratu et al. 2000; Hoch 2002; Laroche et al. 2005; Peck and Childers 2003). Not being able to see or touch products can complicate the evaluation process and lead to greater uncertainty and a higher 
perceived risk of online purchases (Laroche et al. 2005; Pauwels et al. 2011; Weathers et al. 2007). This may increase the transaction costs of buying sensory products in the online store (Gupta and Kim 2010), and result in relatively lower online purchase shares of sensory categories compared to other categories (Chintagunta et al. 2012).

Shopping convenience. The shopping convenience advantage of online stores may especially benefit bulky and heavy categories, as online shopping eliminates the burden of physically handling these products, e.g., putting them into the basket and carrying them home. The resulting increase in transaction utility can lead to disproportionately higher online category purchase shares of bulky and heavy categories (Chintagunta et al. 2012).

\section{Moderating impact of online buying experience}

Because online shopping for groceries is lagging behind compared to other categories (McPartlin and Dugal 2012), many consumers are still relatively new to and unfamiliar with the online grocery store environment and shopping process. Consequently, they may adjust their purchase behavior as they gain more experience with buying groceries online. For this reason, and given that the online purchase tendency can differ across grocery categories, we include category-specific online buying experience as a moderator of category allocation decisions. Based on the previous discussion and consumer behavior literature, we postulate that experience can work in different ways: (i) reduce the uncertainty and perceived risk of online purchases (Frambach et al. 2007; Kim et al. 2008; Iyengar et al. 2007), (ii) help to gain additional factual and choice-related knowledge (Alba and Hutchinson 1987; Iyengar et al. 2007) and (iii) involve a learning process in which consumers adjust their evaluation and decision processes to the new

store environment (Degeratu et al. 2000; Hamilton and Thompson 2007; Hoch 2002). Experience 
can thus attenuate as well as reinforce category differences in online purchase share, or it may not affect the allocation pattern at all when no risk is involved or no learning process is needed.

We expect that experience has a mitigating effect on the reluctance to buy sensory categories online. First, conditional upon a positive and satisfying outcome, experience can enhance confidence in the online purchase outcome and increase trust in the retailer's selection and delivery process (cf. Kim et al. 2008; Urban et al. 2009). Second, experience helps with 'learning' to infer missing information from other - verbal and visual - cues that can be easily accessed in the online store and that are diagnostic of the product's quality (e.g., quality labels, product characteristics that act as a quality cue such as brand names and expiration dates) (Degeratu et al. 2000; Laroche et al. 2005; Peck and Childers 2003).

On the other hand, we expect that consumers may not be able to accurately assess assortment size and price differences between the online and offline channel from the start. For low involvement, multi-category purchases such as groceries, consumers may not be able or motivated to go through a complete evaluation of the entire assortment, and hence, may not be fully aware of actual assortment or price differences. After some online purchases in the category, they may gradually become aware that some items are missing or only available in the online assortment, or that some items are higher or lower priced online (Alba and Hutchinson 1987; Hoyer and MacInnis 2010). As a result, consumers may adjust their channel preferences and purchase allocation pattern, and these experience-based corrections in assortment and price perceptions may thus reinforce initial assortment and price effects.

Finally, we expect that sales promotions, in-store stimuli and the convenience of buying bulky/heavy categories are easy to evaluate without much online shopping experience. Hence, 
there is no incentive to learn and adjust the shopping process, and the reaction to these factors is expected to be immediate and independent of a consumer's online shopping experience.

\section{Model}

To examine multichannel category allocation decisions, we focus on the online channel's share in category spending (SCS), taking overall spending at the chain as given. Using a relative instead of absolute measure of online category expenditures has the advantage of removing the effect of customer and category differences in total spending. In line with multiple store shopping literature (Gijsbrechts et al. 2008; Vroegrijk et al. 2013), we concentrate on allocation patterns over a longer period of time (i.e., bi-weekly periods, t), rather than category purchase decisions on a visit-by-visit basis. In addition, because consumers only have to decide how to allocate their purchases within this two-week period when they plan to buy the category ànd when they visit both channels, we focus on observations with (i) a category need (i.e., an online and/or offline purchase in the category) and (ii) an online and offline store visit (i.e., a multichannel shopping period where consumers are in the opportunity to buy the product online and/or offline, and allocation is not pre-defined to $0 \%$ or $100 \%$ ). This allows us to eliminate both the effect of a consumer's general online buying tendency (decision to visit the online store) and the effect of category purchase decisions on observed category allocations.

The online channel's share in spending for category c in period $\mathrm{t}$ for household $\mathrm{i}\left(S C S_{i t}^{c}\right)$ is defined and estimated over all categories simultaneously (pooled estimation) $)^{3}$ :

\footnotetext{
${ }^{3}$ To simplify the discussion, we use an overall index $t$ and $\mathrm{c}$ for time periods and categories respectively. As we only include multichannel purchase occasions (periods where household i visited both channels), and categories for which the household made a purchase within this period, the time index is actually household-specific while the category index is household- plus time-specific.
} 
(1) $\quad S C S_{i t}^{c}=\frac{e^{U_{i t}^{c}}}{1+e^{U_{i t}^{c}}}$.

By using a logistic model in Equation (1), we ensure that the values of the outcome variable are restricted within the zero-one range. To linearize the model, we use the method of log-centering (Cooper and Nakanishi 1996; Lesaffre et al. 2007), that has been applied in many other studies (see e.g., Cleeren et al. 2013; Leenheer et al. 2007):

(2) $\ln \left[\frac{S C S_{i t}^{c}}{1-S C S_{i t}^{c}}\right]=V_{i t}^{c}+\mu_{i t}^{c}$.

To avoid that the dependent variable in Equation (2) is equal to the $\log$ of zero $\left(S C S_{i t}^{c}\right.$ equal to zero) or an undefined value (division by zero, $S C S_{i t}^{c}$ equal to one), we add a small amount to the numerator and denominator of Equation (2) (cf. Bass et al. 2009; Cleeren et al. 2013), such that:

$$
\ln \left[\frac{S C S_{i t}^{c}+0.001}{1-S C S_{i t}^{c}+0.001}\right]=V_{i t}^{c}+\mu_{i t}^{c}
$$

We use consumer, marketing mix and experience as explanatory variables:

$$
\begin{gathered}
V_{i t}^{c}+\mu_{i t}^{c}=\left[\gamma_{0 i}+\gamma_{1} * \operatorname{STS}_{i t}+\gamma_{2} * \operatorname{Exp}_{i t}^{c}+\gamma_{3} * \text { Usage }_{i}^{c}\right] \\
+\left[\delta_{1} * \text { Ass }^{c}+\delta_{2} * \text { Price }^{c}+\delta_{3} * \text { Promo }^{c}+\delta_{4} * \text { ISS }^{c}\right] \\
+\left[\delta_{5} * \text { Sens }^{c}+\delta_{6} * \text { Bulky_Heavy }^{c}\right]+\mu_{i t}^{c} .
\end{gathered}
$$

The first square brackets in Equation (3) capture consumer characteristics that account for individual differences in the tendency to allocate purchases in category c to the online channel, including a consumer-, category- and time-specific online buying experience variable $\left(E x p_{i t}^{c}\right)$, and a usage variable capturing the consumer's overall experience with the category $\left(U_{s a g e}^{c}\right)$. In addition, we include the online store's share in total spending in period t for consumer i $\left(S T S_{i t}\right)$, defined as the overall percentage of online purchases in total grocery expenditures of consumer $i$ at the chain in period t. Including this variable allows to capture category-specific deviations from the overall online/offline allocation pattern that result from channel differences in 
acquisition and transaction utility. The second square brackets include variables that may entail channel differences in acquisition utility, i.e., category-specific channel differences in assortment size $\left(A s S^{c}\right)$, price $\left(\right.$ Price $\left.^{c}\right)$, promotion $\left(\right.$ Promo $\left._{t}^{c}\right)$, and in-store stimuli $\left(I S S^{c}\right)$. The third square brackets capture the effect of transaction cost related characteristics, including whether the category is a sensory $\left(\right.$ Sens $\left.^{c}\right)$, or bulky/heavy $\left(B u l k y \_H e a v y^{c}\right)$ category. We describe the operationalization of these variables in the Data section. $\mu_{i t}^{c}$ is a normally-distributed error term.

To incorporate the effect of category-specific online buying experience, we use a model with varying coefficients (Foekens et al. 1999; Kopalle et al. 1999). The parameters of the category-specific variables are made a function of experience, allowing the effect to increase or decrease with higher levels of online buying experience in the category:

$$
\delta_{q}=\delta_{q 0}+\delta_{q 1} * \operatorname{Exp}_{i t}^{c},(\mathrm{q}=1-6)
$$

Next, because channel differences in assortment and price variables can be inspired by management expectations on multichannel purchase behavior, we control for potential endogeneity of these variables using a control function approach (Luan and Sudhir 2010; Petrin and Train 2010) ${ }^{4}$. Appendix A provides more detailed information. Our final model includes the residuals of the control function models of assortment $\left(\right.$ Res_Ass $\left.^{\mathrm{c}}\right)$ and price (Res_Price $\left.{ }^{\mathrm{c}}\right)$ as additional variables:

$$
\begin{aligned}
& V_{i t}^{c}=\left[\gamma_{0 i}+\gamma_{1} * S T S_{i t}+\gamma_{2} * \operatorname{Exp}_{i t}^{c}+\gamma_{3} * \operatorname{Usage}_{i}^{c}\right]+\left[\delta_{1} * \text { Ass }^{c}+\delta_{2} * \text { Price }^{c}+\delta_{3} *\right.
\end{aligned}
$$

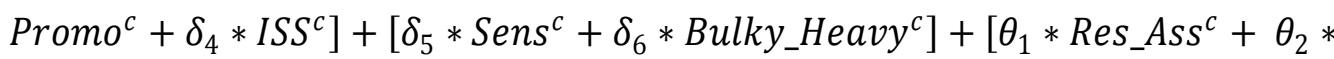

$$
\begin{aligned}
& \text { Res_Price } \left.{ }^{c}\right] \text {. }
\end{aligned}
$$

\footnotetext{
${ }^{4}$ We expect that the endogeneity problem is especially important for the assortment and price variables because these are typically long-term strategic decisions where the offline channel's price and assortment is taken into account. Promotions, on the other hand, are expected not to have an endogeneity problem because they are shortterm decisions made independently from the decisions in the other channel. Estimation of a control function model for promotion intensity indeed provided extremely low explanatory value, and robustness checks confirmed that no improvements in fit or substantive results can be gained when controlling for endogeneity in the promotion variable.
} 
Finally, to capture unobserved heterogeneity, we use (i) latent-class estimation, allowing the parameters of explanatory variables to vary across latent segments (Andrews et al. 2002; Kamakura and Russell 1989), and (ii) a random coefficient approach by introducing a standard normally distributed latent factor $\left(F_{i}\right)$, allowing intercepts to vary across households (Vermunt and Magidson 2013). We formulate the household-specific intercept in Equation (3) as:

$$
\gamma_{0 i}=\gamma_{01}+\gamma_{02} * F_{i}
$$

We use Latent GOLD® software to compute the latent factor and estimate the coefficient $\gamma_{02}$ (while fixing the value of the standard deviation of the latent factor to 1; see Vermunt and Magidson 2013, p.100-101). Latent GOLD® uses a factor-analytic parameterization of the random-intercept model. The parameter $\gamma_{02}$ can be interpreted as the standard deviation of the random intercept. The significance of the parameter gives an indication of the importance of household differences in the share they allocate to the online store. A non-significant parameter, corresponding to a zero standard deviation of the intercept, points to homogeneous online purchase tendencies.

The log-likelihood function defined by Equations (3') and (2)-(6) is given by:

$$
\text { (7) } L L=\sum_{i} \ln \left\{\sum_{s} P_{i}(s) \prod_{t} \prod_{c} f\left(\ln \left(\frac{S C S_{i t}^{c}+0.001}{1-S C S_{i t}^{c}+0.001}\right) \mid V_{i t, s}^{c}\right)\right\}
$$

where $V_{i t, s}^{c}$ is the segment-specific version of Equation (3') that allows for differences between segments in their sensitivity to factors that affect channel allocation decisions, $f$ is the joint density function of the normal distribution and $\mathrm{P}_{\mathrm{i}}(\mathrm{s})$ is the (a priori) probability that household $\mathrm{i}$ belongs to segment $\mathrm{s}$, which is defined as:

(8) $P_{i}(s)=\frac{e^{\varphi_{S}}}{\sum_{r=1}^{R} e^{\varphi_{r}}}$ 
where $\varphi_{s}$ reflects the size (importance) of segment $s$ and $\mathrm{R}$ is the total number of segments. Equation (7) indicates that segments are defined over a household's complete purchase history, i.e., over all time periods $\mathrm{t}$ and categories $\mathrm{c}$.

\section{Data}

Our data come from a major European grocery chain which has a prominent presence throughout the country and is one of the leading offline and online grocery retailers. As we focus on online and offline stores of a single retail chain, online and offline assortments mainly differ in size and not in composition (the online assortment is a subset of the offline assortment), and category prices are directly comparable (price differences are not linked to quality differences). When an online order gets placed, professional shoppers (pickers) fill the order from an independent warehouse; the retailer then delivers the order to the place and at the time specified by the consumer. The online store operates independently and is given full control over merchandising decisions. As a consequence and notwithstanding the similarities in chain policy, there are differences between the online and offline channel in assortment size, product prices and promotional actions.

We used loyalty card information to link online and offline purchase data over a one-year period (2006). To get stable model estimations and a representative sample of multichannel shoppers, we focus on households that made (i) at least two online and two offline store visits during the estimation period (thereby excluding one-off online trial purchases), and (ii) at least two purchases in the category (irrespective of the channel, to include heavy as well as light buyers of the category). In the model estimations, we made a further selection and only focus on bi-weekly periods (of retained households) with a visit to both channels ánd a category purchase 
in at least one of the channels. During these periods, the household needs the category, but allocation is not predetermined as would be the case in online-only (100\% online) or offline-only ( $0 \%$ online) periods. Table 1 gives an overview of the 25 frequently-purchased categories that were used, and indicates per category the number of households and observations retained.

[Insert Table 1 about here]

As Table 1 indicates, most categories that we examined are purchased during multichannel shopping occasions on a regular basis: on average $32 \%$ of all transactions are multichannel transactions (min. $24 \%$ for vegetables and max. $40 \%$ for water). Online-only shopping occasions occur least often (on average 12\%; min. $1 \%$ for fresh fish and max. $20 \%$ for water), while offline-only shopping occasions are most common (on average 57\%; min. $40 \%$ for water and max. $70 \%$ fresh fish). In general, consumers are more likely to visit (and purchase categories in) the offline channel than the online channel: the average number of bi-weeks per year with a purchase in the category equals 4.66 for the online channel and 9.69 for the offline channel. The online category share of spending equals $33 \%$ (min. $5 \%$ for fresh fish and max. $56 \%$ for water) across all bi-weekly periods with a category purchase and increases to $51 \%$ (min. $8 \%$ for fresh fish and max. $84 \%$ for water) for the multichannel periods only.

Table 2 describes the details of the variable operationalization. The share in category spending is operationalized as the ratio of online purchases in category $\mathrm{c}$ by consumer $\mathrm{i}$ in period t, divided by the consumer's overall category purchases during that period in the online and offline channel combined. As we focus on multichannel shopping occasions, consumers may distribute purchases over both channels (share of online category spending between zero and one), but they can also decide to allocate the purchases to one of both channels (share of online category spending equal to zero or one). 
[Insert Table 2 about here]

Marketing mix information was obtained via the retailer. As a measure of channel differences in assortment size, we used the ratio of the assortment size (number of SKUs) of category $\mathrm{c}$ in the online store divided by the assortment size (number of SKUs) of category $\mathrm{c}$ in the offline store ${ }^{5}$. This ratio is comparable across categories, and is smaller (larger) than one when the online assortment is smaller (larger) than the offline assortment. To capture the category price variable, we compute the difference in average category prices between online and offline stores (average price for the set of category products that is available in both channels) ${ }^{6}$. To capture promotion effects, we use the share in overall category promotions of the online store, defined as the number of SKUs on promotion in category $\mathrm{c}$ at time $\mathrm{t}$ in the online store, divided by the number of SKUs on promotion in category $\mathrm{c}$ at time $\mathrm{t}$ in the online and offline store combined. This eliminates the effect of differences in assortment size and makes the variable comparable across product categories. The in-store stimuli variable is operationalized as a dummy variable that is equal to one when purchases of category $\mathrm{c}$ are often unplanned and strongly influenced by in-store stimuli. This classification was checked by survey data, where a representative convenience sample of respondents assessed on a 7-point Likert scale the extent to which a category is bought spontaneously when seeing it in the store $(\mathrm{t}=-7.41, \mathrm{p}<.01)$. The categories that were classified as 'high in-store sensitive' match those where the majority of the respondents indicated they often buy these categories without having planned the purchase.

Sensory and bulky/heavy characteristics are captured by dummy variables equal to one when the

\footnotetext{
${ }^{5}$ We have detailed offline assortment and price information for one time period only and therefore had to use timeindependent price and assortment variables. However, for the retailer under consideration, regular price and assortment within a category hardly changed during our observation period. In addition, we only have category-level data and are constrained in making marketing mix variables individual-specific (e.g., by using SKU-weights).

${ }^{6}$ We explicitly checked whether price differences between the online and offline channel were related to the online assortment reduction strategy (e.g., only the more expensive items in the online assortment) and found that this was not the case since the online assortment of all categories covers a range of items with different price levels.
} 
category is classified as sensory or bulky/heavy. Like for the in-store stimuli variable, we checked the sensory classification with survey data, where a representative convenience sample of respondents was asked to rate each category on the importance of physical inspection of sensory attributes prior to purchase $(t=-15.684, p<.001)$. Bulky/heavy categories are categories for which more than $75 \%$ of online shoppers in our dataset buy package sizes that exceed a certain weight (e.g., multi-packs) or that are considered as bulky according to management.

To capture online buying experience, we use the weighted sum of previous online purchases in the category (cf. Foekens et al. 1999), and use an initialization period of 26 biweeks to compute the starting value ${ }^{7}$. The experience variable increases with the number of previous purchases (frequency effect), but each previous purchase receives a weight that becomes smaller when the purchase occurred longer ago (recency effect) (see Table 2). The resulting experience measure is larger when the customer has purchased the category more often and more recently in the online store, and varies substantially across households and over time (range $=[0,2.33]$, mean $=.46$, standard deviation $=.58)$. Finally, category-specific usage is operationalized as the average spending of consumer $\mathrm{i}$ in category $\mathrm{c}$ divided by the global average for category $\mathrm{c}$, to make the variable comparable across categories.

Table 3 classifies the categories according to marketing mix differences and sensory, heavy/bulky and impulse characteristics. The classification clearly shows that there is sufficient variation across the different characteristics. On average, online assortments tend to be smaller while online prices tend to be higher. Several other online grocery chains follow a similar strategy (Cheng 2010). The degree of assortment reduction and the size of the online price premium, however, substantially differs across categories.

\footnotetext{
${ }^{7}$ We have one year of data (2006) on online and offline category purchases that allows us to derive multichannel occasions. But, we have one additional year (2005) of online data that allows us to initialize the experience variable.
} 
[Insert Table 3 about here]

\section{Empirical Results}

Estimation results of the control function models can be found in Appendix A. We estimated the endogeneity-corrected version of the SCS model with a varying number of latent classes. Although additional segments provide a further improvement in goodness-of-fit, there is a clear elbow (Figure 2) in the graph of the Bayesian Information Criteria (BIC) statistic at four segments with additional segments providing only a minor improvement in fit. The BIC statistic also indicates that the correction for endogeneity improves the results (BIC of four-segment model without vs. with endogeneity correction: 253836 vs. 253828). Overall the model explains the differences in allocation pattern across categories and consumers very well (pseudo $\mathrm{R}^{2}=.48$ ). To investigate to what extent product category characteristics, experience effects and household characteristics contribute to the model's explanatory power, we did a variance decomposition. Results of partial model estimations indicate that each of these explanatory variables significantly improves goodness-of-fit, both based on $R_{a d j}^{2}$ and Likelihoodratio statistics. The increase in $R_{a d j}^{2}$ (LR statistic) for instance, amounts to .18 ( $\left.\mathrm{LR}=10574 ; \mathrm{p}<.005\right)$ for product characteristics (compared to an intercepts-only model), to .04 ( $\mathrm{LR}=2888, \mathrm{p}<.005)$ for experience (compared to a model with intercepts and product characteristics) and to .08 ( $\mathrm{LR}=5594, \mathrm{p}<.005)$ for household characteristics other than experience (compared to a model with intercepts, product characteristics and experience effects). We also conducted several robustness checks to verify the validity of our model and the consistency of our findings. They are summarized in Appendix B. Table 4, Panel A reports the estimation results for the homogeneous model as well as for the four-segment model. As we will focus on the results of the four-segment model, we 
first describe the differences across segments, and next provide a general discussion of the main and interaction (experience) effects.

[Insert Figure $2 \&$ Table 4 about here]

Overall, in terms of segment differences, we find that segment 1 customers (29\% of all customers) are most sensitive to purchase allocation factors (assortment, promotion, in-store stimuli, sensory and bulky/heavy), and make the strongest (effect-reducing) adjustments when they gain more online buying experience. Segment 2 customers $(22 \%)$ are sensitive to price differences, in-store stimuli, sensory and bulky/heavy allocation factors, but are less sensitive to experience effects than segment 1 , which can be explained by the low overall increase in online buying experience (see below). Segment 3 and 4 (14\% and 35\% of the customers respectively) are both much less sensitive to the examined allocation factors than customers of the other segments (significant effects are limited to in-store stimuli and bulky/heavy), but differ between each other in online buying experience reactions. While higher levels of experience have almost no effect on segment 3 consumers, segment 4 customers adjust their reaction to channel price differences, in-store stimuli, sensory and bulky/heavy categories in a positive way.

We thus observe differences between consumer segments in online buying experience effects: (i) attenuating effects that reduce category differences in purchase allocation (segment 1 and 4), (ii) reinforcing effects that increase category differences in purchase allocations (segment 2), and (iii) no or limited adjustment effects (segment 3). Table 4, Panel B provides an overview of segment characteristics that can explain these differences in reactions. Segments 1 and 4 both allocate a large share of purchases to the online channel, and their level of online buying experience increases substantially over the estimation period. In addition, segment 4 already had a relatively high level of experience at the start, which can explain the smaller number of 
significant main effects (the experience-reducing effects have to some extent already taken place). We label segment 1 as 'new online grocery fans' and segment 4 as 'experienced online grocery fans'. Compared to segment 1 and 4, segment 2 and 3 both allocate a low(er) share to the online channel in general, which may explain the absence of experience-reducing effects. In contrast to segment 3 , segment 2 customers' online experience level remains low, which may additionally signal a low interest in the online channel and thus could explain experiencereinforcing effects. We label segment 2 as 'online grocery sceptics' and segment 3 as 'occasional online grocery shoppers'.

In terms of model estimation results, we find that the latent factor coefficient is significant for all segments, indicating that there is still some 'unobserved' (unexplained) variation across households in the overall tendency to spend a larger SCS online. However, comparison of the magnitude of this coefficient (which captures the standard deviation of the intercept over households; see model section) with that of the segment-specific intercept (i.e., the constant which captures the average effect) indicates that the model explains a large part of the (observed) household variation in online buying tendency. We further obtain significant and expected positive effects for the control variables, share in total spending $\left(S T S_{i t}\right)$ and experience $\left(\operatorname{Exp}_{i t}^{c}\right)$, across all four segments. The category usage level $\left(\operatorname{Usage}_{t}^{c}\right)$, on the other hand, is negative and significant for two out of four segments. A possible explanation for this negative effect could be that heavy users, who buy the category more frequently, buy a lower share online because they have more opportunities to buy the category in the offline store.

In terms of the impact of acquisition utility factors, we find that assortment differences have a weakly significant and positive main effect in one segment (segment $1, \delta_{10, s 1}=6.710$, $\mathrm{p}<.10$ ), and a significant and positive experience interaction effect for two other segments 
(segment 2: $\delta_{11, \mathrm{~s} 2}=5.439, \mathrm{p}<.10$; segment $3: \delta_{11, \mathrm{~s} 3}=1.729, \mathrm{p}<.01$ ). These results indicate that the online channel captures a larger share of category purchases in categories where the online assortment is more similar in size to the offline assortment for 3 out of the 4 segments $(65 \%$ of the consumers), but for some customers (segment 2 and 3,36\%) only after they gain more online buying experience. To assess the overall effect of assortment differences, these results have to be evaluated in combination with the endogeneity correction effects. The coefficient of the assortment control function residuals is only significant at $10 \%$ for segment 3 , indicating that there is no serious endogeneity problem for the assortment variable (Wooldridge 2013). Overall, these results indicate that consumers are sensitive to assortment differences (except for segment 4), and that actual differences in online and offline assortments are still mainly guided by other managerial considerations than expected customer reactions (no substantial endogeneity effect).

For price differences, we find a negative and significant effect for the online grocery sceptic segment $2\left(\delta_{20, \mathrm{~s} 2}=-1.564, \mathrm{p}<.01\right)$, and no significant effect for the other three segments. Yet, in contrast to assortment, we obtain significant effects for the residual of the price correction function in all segments except segment 1 . This not only indicates that the price variable is endogeneous, but also that the online-offline price differences are in line with category differences in price sensitivity. This is confirmed by the results of a model without endogeneity correction, where price effects are negative and significant for three out of four segments. The moderating effect of experience is - contrary to our expectations - positive and significant for the grocery fan segments 1 and $4\left(\delta_{21, \mathrm{~s} 1}=1.041, \mathrm{p}<.01 ; \delta_{21, \mathrm{~s} 4}=1.050, \mathrm{p}<.01\right)$ and not significant for the other two segments. So, while the price sensitivity of the online grocery sceptic segment 2 consumers does not change their allocation pattern when they gain additional experience (and online price knowledge), consumers of grocery fan segments 1 and 4 tend to adjust their 
spending levels to channel price differences in an upward way (i.e., they increase the online share for categories with larger online price premiums).

Promotions do not lead to higher spending levels in the category except for the new online grocery fan segment $1\left(\delta_{30, s 1}=.737, \mathrm{p}<.01\right)$, who may pay more attention to online promotional stimuli than online grocery sceptics or experienced online grocery fans. This is also in line with previous observations that - in general - promotions predominantly affect brand choices, and have a much smaller or no effect on category demand and store choices (Bell et al. 1999). As expected, the effect does not change with higher levels of online buying experience as none of the interactions with experience are significant.

Categories for which in-store stimuli are important, are purchased less easily in online stores as indicated by the negative and significant effect on SCS decisions in each of the segments. For the occasional online grocery shopper segment 3, this effect does not change with higher levels of experience (they already adapted their allocation patterns prior to the estimation period) while experience reinforces the negative effect for the online grocery sceptic segment 2 $\left(\delta_{41, \mathrm{~s} 2}=-3.092, \mathrm{p}<.01\right)$. For grocery fan segments 1 and 4 , the effects are only marginally significant and very small (segment $1: \delta_{41, \mathrm{~s} 1}=-.650, \mathrm{p}<.10$; segment $4: \delta_{41, \mathrm{~s} 4}=-.367, \mathrm{p}<.10$ ). Overall, experience thus appears to have a negligible effect on the sensitivity to in-store stimuli. In terms of the impact of transaction utility factors, the results provide support for the assumption that consumers will allocate a relatively low share of sensory category purchases to the online store: three out of four segments have a significant negative effect for sensory categories $\left(\delta_{50, \mathrm{~s} 1}=-4.527, \mathrm{p}<.01 ; \delta_{50, \mathrm{~s} 2}=-3.379, \mathrm{p}<.01 ; \delta_{50, \mathrm{~s} 3}=-1.695, \mathrm{p}<.10\right)$, and not for the experienced online grocery fan segment 4 . Experience has, as expected, a positive effect on the share of sensory purchases allocated to the online store for grocery fan segments 1 and 4 
$\left(\delta_{51, \mathrm{~s} 1}=2.054, \mathrm{p}<.01 ; \delta_{51, \mathrm{~s} 4}=.47, \mathrm{p}<.05\right)$. Experience has no effect on the online share in sensory purchases for the online grocery sceptic segment 2, and a negative reinforcing effect for the occasional online grocery shopper segment $3\left(\delta_{51, \mathrm{~s} 3}=-0.519, \mathrm{p}<.05\right)$, possibly as a result of negative experiences with online sensory purchases.

In line with its shopping convenience benefit, the online store attracts a relatively larger share of bulky and heavy category purchases for all segments $\left(\delta_{60, \mathrm{~s} 1}=2.118, \mathrm{p}<.01 ; \delta_{60, \mathrm{~s} 2}=5.212\right.$, $\left.\mathrm{p}<.01 ; \delta_{60, \mathrm{~s} 3}=4.156, \mathrm{p}<.01 ; \delta_{60, \mathrm{~s}}=.681, \mathrm{p}<.01\right)$. In contrast to our expectations, however, the effect weakens in three out of four segments $\left(\delta_{61, \mathrm{~s} 1}=-.848, \mathrm{p}<.01 ; \delta_{61, \mathrm{~s} 2}=-9.724, \mathrm{p}<.01 ; \delta_{61, \mathrm{~s} 3}=-\right.$ $.762, \mathrm{p}<.01)$ and strengthens in the other segment $\left(\delta_{61, s 4}=.552, \mathrm{p}<.01\right)$. Consumers of the experienced grocery fan segment 4 that were somewhat more conservative at the start (smaller magnitude of main effect for bulky/heavy) appreciate the shopping convenience benefit more and more over time. Consumers of the other segments that were more convinced about the shopping convenience benefit at the start (larger magnitude of main effect for bulky/heavy) gradually lower the online share of bulky and heavy categories. While the convenience effect of heavy/bulky categories remains positive and significant for all segments, the difference in effect across segments becomes smaller as consumers gain more experience with buying these categories online, but still varies substantially across the four segments.

\section{Discussion and conclusions}

The objectives of this research were twofold. First, we wanted to provide a comprehensive analysis of the factors that affect purchase allocation decisions of multichannel grocery shoppers, thereby controlling for potential endogeneity biases in marketing mix effects. 
Second, we wanted to investigate the effect of online buying experience and test whether and for which factors, experience can have an online purchase enhancing or rather reducing effect.

\section{Factors of multichannel purchase allocation decisions}

The results confirm that acquisition and transaction utility based factors can influence the share of category purchases that is allocated to the online store. The large majority of multichannel shoppers $(65 \%)$ is less inclined to buy categories online for which the online store offers a less attractive (smaller) assortment. Channel differences in price and promotion intensity have respectively a negative and positive effect on a smaller subset of multichannel shoppers (22\% price, $29 \%$ promotion). All consumers are less sensitive to in-store incentives and buy substantially less impulse categories in the online channel compared to the overall allocation of grocery purchases to the online store. In addition to these traditional allocation factors, we find significant effects of intrinsic category characteristics that affect online transaction utility. As expected, the majority of consumers $(65 \%)$ is less inclined to buy sensory products online because of the higher perceived online purchase risk, and all consumers purchase substantially more heavy/bulky products to take advantage of online convenience benefits.

\section{The moderating effect of category-specific online buying experience}

Previous research on general online purchase barriers has stressed the positive impact of online experience in reducing the resistance to buy online, caused by factors such as the financial risk of online transactions (Frambach et al. 2007; Kim et al. 2008; Iyengar et al. 2007). We observe a similar attenuating effect of category-specific online buying experience for risk related category characteristics. The negative effect of a lack of sensory information gradually 
disappears for about $30 \%$ of the multichannel shoppers ('new online grocery fans'), when they gain more experience with buying sensory categories online and get accustomed to select these products without prior physical inspection.

Yet, in contrast to what has been found for online buying experience in general, we show that more experience may also lead to adverse effects for marketing mix based differences in acquisition utility between both channels. Given the customers' low involvement with grocery purchases and high time pressure during a multi-category shopping task, they are often not prepared to engage in complex evaluations, such as detailed comparisons of online-offline assortments. Instead, consumers gain a better insight into actual assortment differences through an experience-based learning process. As a result, more than one third of the respondents ('online grocery sceptics' and 'occasional online grocery shoppers') gradually reduce their online purchases of categories with a smaller online assortment in favor of the offline channel, as they become more clearly aware of the restrictions in choice variety. Channel differences in price also have a stronger impact on allocation patterns for some consumers when they gain experience, but in contrast to our expectations, the interaction effect with experience is positive (larger share of category spending for categories with a higher online price) for 'new' and 'experienced online grocery fans'. The results of the endogeneity correction indicate that for segment 4 ('experienced online grocery fans'), management has anticipated channel differences in the online willingness-to-pay correctly (significant price residual coefficient). The results for segment 1 ('new online grocery fans') suggest that these consumers are more quality-oriented (e.g., strong positive main effect of assortment) and not very sensitive to price (no significant main or endogeneity correction effect). This can explain the lack of a negative effect of experience on online purchase shares of categories with a larger price difference. 
As expected, we did not find any moderating effect of experience on the reaction to channel differences in promotion intensity, which are easy to evaluate from the start and do not require any learning and adjustment process. While we expected a similar (non-significant) effect for impulse purchases triggered by in-store stimuli, and online shopping convenience advantages of heavy/bulky categories, experience has a negative effect (marginally significant) for $51 \%$ of the consumers on impulse purchases and $65 \%$ for heavy/bulky categories. For impulse purchases, this can probably be explained by the fact that consumers unfamiliar with the online grocery shopping environment have to search more to find the needed products, which increases their exposure to in-store stimuli. For heavy/bulky categories, experience attenuates the allocation effect for most consumers, but reinforces it for those who initially made less use of the online convenience advantage. As a result, the difference across consumer segments becomes smaller, but the effect remains significant and positive for all consumers.

In terms of differences across consumers, results show that there are clear differences in how segments change allocation patterns when gaining more experience. Segments that are enthusiastic about online shopping and its benefits (new and experienced online grocery fans) are more likely to show attenuating effects that reduce category differences in purchase allocation. Segments that use the online store less frequently (online grocery sceptics and occasional online grocery shoppers) are less likely to adjust allocation over time, and can even face reinforcing effects that increase category differences in allocations when their experience level remains low.

\section{Managerial implications}

Grocery retailers increasingly recognize the importance of online stores to retain the existing customer base, and nowadays most of the large chains have opened an online store next 
to their traditional offline supermarkets. By offering an additional distribution channel that complements offline stores and offers unique benefits (such as greater accessibility and more convenience and time saving; Chu et al. 2010; Gupta and Kim 2010), they hope to increase their value proposition and gain a competitive advantage over single-channel retailers (Chintagunta et al. 2012; Kabadayi et al. 2007; Zhang et al. 2010). Yet, to assess and improve the profitability of the multichannel strategy, retailers not only need to understand whether and why customers will adopt the new online channel, but also which share of the shopping baskets the online store can attract to cover its relatively high operational costs. Our findings contribute to a better understanding of the factors underlying category differences in online performance and may in this way help to define appropriate promotional and corrective actions that can be taken to stimulate online purchases of less successful categories.

A first important insight that can be derived from our findings is that different actions may be needed to stimulate online purchases. For marketing mix related factors, retailers should realize that multichannel shoppers may react negatively to excessive online assortment reductions, especially when they gain more online buying experience. Large assortment reductions can then have an important negative effect, implying that online retailers may have to invest in upgrading online assortments to better match the offline product offer. Online shoppers are, on the other hand, more willing to tolerate online price premiums when they gain more online buying experience (and are thus better able to appreciate the online shopping advantages). Nevertheless, for a substantial segment of consumers (about 22\%), high online price premiums do significantly reduce the attractiveness of the online offer. While experience does not reinforce this effect as we expected, it does not attenuate it either. 
The lower sensitivity to in-store incentives in the online environment calls for promotional tactics that are better tailored to the specific online environment (e.g., personalized promotions, cross-selling opportunities, tailored in-store displays; Bellman et al. 2013; Breugelmans and Campo 2011; Punj 2011) and that may stimulate purchases of impulse categories in the online channel. In addition, marketing communication can play an important role in reducing the perceived risk and uncertainty of online purchases and help customers to adjust decision rules to the new shopping environment (Weathers et al. 2007). Retailers can, for instance, use customer reviews or other electronic word-of-mouth to highlight the positive experiences of other shoppers with buying sensory categories online (Jiménez and Mendoza 2013; Purnawirawan et al. 2012). They can also help consumers by providing substitute information cues (such as expiration dates and quality labels) and by clarifying their usefulness in judging the product quality of sensory categories. Lastly, retailers can stress the online convenience benefits in their marketing communications to further spur the higher tendency of buying heavy/bulky products in the online channel.

A second important finding is that experience can have a positive as well as negative effect on the tendency to allocate purchases of specific categories to the online channel. Results show, for instance, that an increase in experience can strengthen the negative effect of assortment differences. This points to potential limitations for retailers when using assortment signaling strategies. While less visible assortment reductions (eliminating less popular items) may initially mask the less attractive online offer, increased experience with buying the categories online may improve the customer's assortment knowledge, and may result in a stronger negative effect on online category allocations. On the other hand, experience may reduce the perceived risk of buying sensory categories online and thereby enhance online purchases of these categories. 
Hence, retailers should strive to enhance positive experiences by stimulating trial and repeat purchases for sensory categories as it offers opportunities to reduce online purchase risk.

Lastly, our findings indicate that there are clear differences in how segments adjust their allocation pattern as they gain more online buying experience. For the segment of frequent online buyers, that are also more willing and open to buy several types of categories in the online store, special loyalty programs could be developed to maintain and reinforce their use of the online channel. For the group of customers that spend a smaller share of grocery products in the online channel and that limit their online purchases to a more restrictive, 'safer' set of categories, extension of online purchases could be aimed for, for instance by stimulating trial purchases of categories with a higher perceived online buying risk (e.g., sensory categories). In this way, these consumers experience (free or with promotion) the positive outcomes of more risky purchases in the online channel, which may help in developing trust in the multichannel retailer's ability to provide a high-quality online service (Urban et al. 2009).

\section{Directions for further research}

Although our study provides interesting new insights into the effect of multichannel category allocation factors, and the moderating effect of category-specific online buying experience, it also has important limitations and points to several interesting areas for additional research. For one, more refined definitions of the category allocation factors could help to obtain a better insight into their effect on online buying behavior. For instance, a focus on assortment composition in addition to size may lead to additional and more refined insights. Likewise, using a household-specific rating of impulsiveness (rather than assuming it is a characteristic that is constant across consumers) or allowing price and assortment to vary over time are important 
refinements that are worthwhile to investigate in more depth. Second, it would be valuable to obtain an in-depth insight into experience effects and how they work, exploring their impact on mediating variables such as learning processes and online retailer trust. Third, an interesting extension of our study would be to explore cross-category effects, such as the potential weakening effect of buying one sensory category as experience reduction for another sensory category, or the accumulated negative effect of encountering a large number of categories with price and assortment disadvantages. Fourth, because of data availability, the focus of this paper is on consumers' shopping behavior in a single chain multichannel grocery context. While this approach has the advantage of eliminating confounding effects of for instance differences in assortment composition and retail strategy across different grocery chains and although previous research has demonstrated that the large majority of multichannel shoppers visit the same chain in the online and offline channel (Melis et al. 2013), a more detailed and complete analysis could be carried out if data of competitive chains would also be available. This would allow for a simultaneous analysis of category allocation decisions over different channels and chains providing a more complete picture of the complex competitive relationships in a multichain multichannel retail context. Finally, examining the impact of category allocation decisions in a non-grocery shopping context (where characteristics like perishability overlap less with sensory characteristics) could offer a useful and interesting extension. 


\section{Acknowledgments}

The authors thank the online grocery retailer who provided the data used in this study, and Huiying He and Kim Goeleven for their help. They further thank Koert van Ittersum, Siegfried Dewitte, Vera Blazevic and Lien Lamey for their helpful suggestions on previous versions of this article.

\section{References}

Alba, Joseph, John Lynch, Barton Weitz, Chris Janiszewski, Richard Lutz, Alan Sawyer, and Stacy Wood (1997), "Interactive Home Shopping: Consumer, Retailer, and Manufacturer Incentives to Participate in Electronic Marketplaces", Journal of Marketing, 61, 3, 38-53.

Alba, Joseph and J. Wesley Hutchinson (1987), "Dimensions of Consumer Expertise", Journal of Consumer Research, 13, 4, 411-454.

Andrews, Rick L., Andrew Ainslie, and Imran S. Currim (2002), "An Empirical Comparison of Logit Choice Models with Discrete Versus Continuous Representations of Heterogeneity", Journal of Marketing Research, 39, 4, 479-487.

Ansari, Asim, Carl F. Mela, and Scott A. Neslin (2008), "Customer Channel Migration", Journal of Marketing Research, 45, 1, 60-76.

Avery, Jill, Thomas J. Steenburgh, John Deighton, and Mary Caravella (2012), "Adding Bricks to Clicks: Predicting the Patterns of Cross-Channel Elasticities over Time", Journal of Marketing, 76, 3, 96111.

Babin, Barry J. and William R. Darden (1995), "Consumer Self-Regulation in a Retail Environment", Journal of Retailing, 71, 1, 47-70.

Baltas, George, Paraskevas C. Argouslidis, and Dionysis Skarmeas (2010), "The Role of Customer Factors in Multiple Store Patronage: A Cost-Benefit Approach", Journal of Retailing, 86, 1, 37-50.

Bass, Frank M., Norris Bruce, Sumit Majumdar, and B.P.S. Murthi (2009), "Wearout Effects of Different Advertising Themes: A Dynamic Bayesian Model of the Advertising-Sales Relationship", Marketing Science, 26, 2, 179-195.

Bell, David R., Jeongwen Chian, and V. Padmanabhan (1999), "The Decomposition of Promotional Response: An Empirical Generalization", Marketing Science, 18, 4, 504-526.

Bellman, Steven, Jamie Murphy, Shiree Treleaven-Hassard, James O'Farrell, Lili Qiu, and Duane Varan (2013), "Using Internet Behavior to Deliver Relevant Television Commercials", Journal of Interactive Marketing, 27, 2, 130-140.

Borle, Sharad, Peter Boatwright, Joseph B. Kadane, Joseph C. Nunes, and Galit Shmueli (2005), "The Effect of Product Assortment Changes on Customer Retention", Marketing Science, 24, 4, 616-622.

Breugelmans, Els and Katia Campo (2011), "Effectiveness of In-store Displays in a Virtual Store Environment", Journal of Retailing, 87, 1, 75-89.

Cheng, Jacqui (2010), "The New Age of Online Grocery Shopping", [available at http://arstechnica.com/web/news/2010/03/the-new-age-of-online-grocery-shopping.ars].

Chintagunta, Pradeep K., Junhong Chu, and Javier Cebollada (2012), "Quantifying Transaction Costs in Online / Offline Grocery Channel Choice", Marketing Science, 31, 1, 96-114.

Chu, Junhong, Marta Arce-Urriza, José-Javier Cebollada-Calvo, and Pradeep K. Chintagunta (2010), "An Empirical Analysis of Shopping Behavior Across Online and Offline Channels for Grocery Products: The Moderating Effects of Household and Product Characteristics", Journal of Interactive Marketing, 24, 4, 251-268.

Chu, Junhong, Pradeep Chintagunta, and Javier Cebollada (2008), "A Comparison of Within-Household Price Sensitivity Across Online and Offline Channels", Marketing Science, 27, 2, 283-299.

Cleeren, Kathleen, Harald van Heerde, and Marnik Dekimpe (2013), "Rising from the Ashes: How Brand and Categories can Overcome Product-Harm Crises," Journal of Marketing, 77, 2, 58-77.

Cooper, Lee and Masao Nakanishi (1996), Market Share Analysis, International Series in Quantitative Marketing, Kluwer Academic Publishers. 
Degeratu, Alexandru M., Arvind Rangaswamy, and Wu Jianan (2000), "Consumer Choice Behavior in Online and Traditional Supermarkets: The Effects of Brand Name, Price, and Other Search Attributes", International Journal of Research in Marketing, 17, 1, 55-78.

Dhar, Ravi (1997), "Consumer Preference for a No-Choice Option", Journal of Consumer Research, 24, 2, 215-231.

Dhar, Sanjay K., Stephen J. Hoch, and Nanda Kumar (2001), "Effective Category Management Depends on the Role of the Categoy", Journal of Retailing, 77, 2, 165-184.

Dholakia, Utpal M., Barbara E. Kahn, Randy Reeves, Aric Rindfleisch, David Stewart, and Earl Taylor (2010), "Consumer Behavior in a Multichannel, Multimedia Retailing Environment", Journal of Interactive Marketing, 24, 2, 86-95.

Frambach, Ruud T., Henk C.A. Roest, and Trichy V. Krishnan (2007), "The Impact of Consumer Internet Experience on Channel Preference and Usage Intentions across the Different Stages of the Buying Process", Journal of Interactive Marketing, 21, 2, 26-41.

Foekens, Eijte W., Peter S. H. Leeflang, and Dick R. Wittink (1999), "Varying Parameter Models to Accommodate Dynamic Promotion Effects", Journal of Econometrics, 89, 1/2, 249-268.

Fox, Edward J. and Stephen Hoch (2005), "Cherry Picking", Journal of Marketing, 69, 1, 46-62.

Gijsbrechts, Els, Katia Campo, and Patricia Nisol (2008), "Beyond Promotion-Based Store Switching: Antecedents and Patterns of Systematic Multiple-Store Shopping", International Journal of Research in Marketing, 25, 1, 5-21.

Gupta, Sumeet and Hee-Woong Kim (2010), "Value-driven Internet shopping: The Mental Accounting Theory Perspective", Psychology \& Marketing, 27, 1, 13-35.

Hamilton, Rebecca W. and Debora Viana Thompson (2007), "Is There a Substitute for Direct Experience? Comparing Consumers' Preferences after Direct and Indirect Product Experiences", Journal of Consumer Research, 34, 4, 546-555.

Hoch, Stephen J. (2002), "Product Experience Is Seductive", Journal of Consumer Research, 29, 3, 448454.

Hoyer, Wayne D. and Deborah J. MacInnis (2010), Consumer Behavior. Mason: South-Western Cengage Learning.

Huffman, Cynthia and Barbara E. Kahn (1998), "Variety for Sale: Mass Customization or Mass Confusion?", Journal of Retailing, 74, 4, 491-513.

Iyengar, Raghuram, Asim Ansari, and Sunil Gupta (2007), "A Model of Consumer Learning for Service Quality and Usage", Journal of Marketing Research, 44, 4, 529-544.

Jiménez, Fernando and Norma A.Mendoza (2013), "Too Popular to Ignore: The Influence of Online Reviews on Purchase Intentions of Search and Experience Products", Journal of Interactive Marketing, 27, 3, 226-235.

Kabadayi, Sertan, Nermin Eyuboglu, and Gloria P. Thomas (2007), "The Performance Implications of Designing Multiple Channels to Fit with Strategy and Environment", Journal of Marketing, 71, 4, 195-211.

Kamakura, Wagner A. and Gary J. Russell (1989), "A Probabilistic Choice Model for Market Segmentation and Elasticity Structure", Journal of Marketing Research, 26, 4, 379-390.

Kim, Dan J., Donald L. Ferrin, and H. Raghav Rao (2008), "A Trust-Based Consumer Decision-Making Model in Electronic Commerce: The Role of Trust, Perceived Risk, and Their Antecedents", Decision Support Systems, 44, 2, 544-564.

Konuş, Umut, Peter C. Verhoef, and Scott A. Neslin (2008), "Multichannel Shopper Segments and Their Covariates", Journal of Retailing, 84, 4, 398-413.

Kopalle, Praveen K., Carl F. Mela, and Lawrence Marsh (1999), "The Dynamic Effect of Discounting on Sales: Empirical Analysis and Normative Pricing Implications", Marketing Science, 18, 3, 317-332.

Laroche, Michel, Zhiyong Yang, Gordon H. G. McDougall, and Jasmin Bergeron (2005), "Internet versus Bricks-And-Mortar Retailers: An Investigation into Intangibility and Its Consequences", Journal of Retailing, 81, 4, 251-267. 
Leenheer, Jorna, Harald van Heerde, Tammo Bijmolt, and Ale Smidts (2007), "Do Loyalty Programs Really Enhance Behavioral Loyalty? An Empirical Analysis Accounting for Self-Selecting Members", International Journal of Research in Marketing, 24, 1, 31-47.

Lesaffre, Emmanuel, Dimitris Rizopulos, and Roula Tsonaka (2007), "The Logistic Transform for Bounded Outcome Scores", Biostatistics, 8, 1, 72-85.

Luan, Jackie and K. Sudhir (2010), "Forecasting Marketing Mix Responsiveness for New Products", Journal of Marketing Research, 47, 3, 444-457.

McPartlin, Sue and Lisa Dugal (2012), "Understanding how US online shoppers are reshaping the retail experience", [available at http://www.pwc.com/en_us/us/retail-consumer/publications/assets/pwcus-multichannel-shopping-survey.pdf].

Melis, Kristina, Katia Campo, Els Breugelmans, and Lien Lamey (2013), "Buying Groceries Online: Which Factors Drive Online Store Choice?", Working Paper.

Neslin, Scott A., Dhruv Grewal, Robert Leghorn, Venkatesh Shankar, Marije L. Teerling, Jacquelyn S. Thomas, and Peter C. Verhoef (2006), "Challenges and Opportunities in Multichannel Customer Management" Journal of Service Research, 9, 2, 95-112.

Neslin, Scott A. and Venkatesh Shankar (2009), "Key Issues in Multichannel Customer Management: Current Knowledge and Future Directions", Journal of Interactive Marketing, 23, 1, 70-81.

Nielsen (2014), "Convenience, Continuous Innovation Key to Retail Succes", [available at http://www.progressivegrocer.com/nielsen-convenience-continuous-innovation-key-retailsuccess\#sthash.huriH3eL.dpuf].

Oppewal, Harmen and Kitty Koelemeijer (2005), "More Choice is Better: Effects of Assortment Size and Composition on Assortment Evaluation", International Journal of Research in Marketing, 22, 1, 45-60.

Pauwels, Koen, Peter S. H. Leeflang, Marije L. Teerling, and K. R. Eelko Huizingh (2011), "Does Online Information Drive Offline Revenues?: Only for Specific Products and Consumer Segments!", Journal of Retailing, 87, 1, 1-17.

Peck, Joann and Terry L. Childers (2003), "To Have and To Hold: The Influence of Haptic Information on Product Judgments", Journal of Marketing, 67, 2, 35-48.

Petrin, Amil and Kenneth Train (2010), "A Control Function Approach to Endogeneity in Consumer Choice Models", Journal of Marketing Research, 47, 1, 3-13.

Pozzi, Andrea (2012), "Shopping Cost and Brand Exploration in Online Grocery", American Economic Journal: Microeconomics, 43, 3, 96-120.

Punj Girish (2011), "Effect of Consumer Beliefs on Online Purchase Behavior: The Influence of Demographic Characteristics and Consumption Values", Journal of Interactive Marketing, 25, 3, 134-144.

Purnawirawan, Nathalia, Patrick De Pelsmacker, and Nathalie Dens (2012), "Balance and Sequence in Online Reviews: How Perceived Usefulness Affects Attitudes and Intentions", Journal of Interactive Marketing, 26, 4, 244-255.

Sethuraman, Raj (2003), "Measuring National Brands' Equity over Store Brands", Review of Marketing Science, 1, 2, 1-28.

Shankar, Venkatesh and Manjit S. Yadav (2010), "Emerging Perspectives on Marketing in a Multichannel and Multimedia Retailing Environment", Journal of Interactive Marketing, 24, 2, 55-57.

Sloot, Laurens M., Dennis Fok, and Peter C. Verhoef (2006), "The Short- and Long-Term Impact of an Assortment Reduction on Category Sales", Journal of Marketing Research, 43, 4, 536-548.

Urban, Glen L., Cinda Amyx, and Antonio Lorenzon (2009), "Online Trust: State of the Art, New Frontiers, and Research Potential", Journal of Interactive Marketing, 23, 2, 179-190.

Van Trijp, Hans C.M., Wayne D. Hoyer, and Jeffrey J. Inman (1996), "Why Switch? Product CategoryLevel Explanations for True Variety-Seeking Behavior", Journal of Marketing Research, 33, 3, 281-292.

Venkatesan, Rajkumar, V. Kumar, and Nalini Ravishanker (2007), "Multichannel Shopping: Causes and Consequences", Journal of Marketing, 71, 2, 114-132. 
Vermunt, Jeroen K. and Jay Magidson (2013), Technical Guide for Latent GOLD 5.0: Basic, Advanced and Syntax. Belmont Massachussetts: Statistical Innovations Inc.

Vroegrijk, Mark, Els Gijsbrechts, and Katia Campo (2013), "Close Encounter with the Hard Discounter: A Multiple-Store Shopping Perspective on the Impact of Local Hard-Discounter Entry", Journal of Marketing Research, 50, 5, 606-626.

Warschun, Mirko (2012), "A Fresh Look at Online Grocery", [available at http://www.atkearney.com/paper/-/asset_publisher/dVxv4Hz2h8bS/content/a-fresh-look-at-onlinegrocery/10192].

Weathers, Danny, Subhash Sharma, and Stacy L. Wood (2007), "Effects of Online Communication Practices on Consumer Perceptions of Performance Uncertainty for Search and Experience Goods", Journal of Retailing, 83, 4, 393-401.

Wolk, Agnieszka and Christine Ebling (2010), "Multi-Channel Price Differentiation: An Empirical Investigation of Existence and Causes", International Journal of Research in Marketing, 27, 2, $142-150$.

Wooldridge, Jeffrey M. (2013), Econometric Analysis of Cross Section and Panel Data, second edition. Cambridge, MA: MIT Press.

Zhang, Jie, Paul W. Farris, John W. Irvin, Tarun Kushwaha, and Thomas J. Steenburgh (2010), "Crafting Integrated Multichannel Retailing Strategies", Journal of Interactive Marketing, 24, 2, 168-180. 
Table 1: Descriptives across the 25 categories

\begin{tabular}{|c|c|c|c|c|c|c|c|c|}
\hline \multirow[b]{2}{*}{ Category } & \multirow{2}{*}{$\begin{array}{c}\# \text { of } \mathrm{HH} \\
\text { retained that } \\
\text { purchase cat. } \geq 2 \\
\text { times and have } \\
\geq 1 \text { multichannel } \\
\text { transaction }\end{array}$} & \multicolumn{3}{|c|}{$\begin{array}{l}\text { \# of bi-weekly periods with category purchase at } \\
\text { (\% of total transactions with category purchase) }\end{array}$} & \multicolumn{2}{|c|}{$\begin{array}{c}\text { Purchase frequency } \\
\text { (average \# of bi-weeks/ } \\
\text { year with cat. purch.) }\end{array}$} & \multicolumn{2}{|c|}{$\begin{array}{l}\text { Online category share of } \\
\text { spending }\end{array}$} \\
\hline & & $\begin{array}{c}\text { both channels } \\
\text { (multichannel } \\
\text { transactions) }\end{array}$ & $\begin{array}{l}\text { online channel } \\
\text { only }\end{array}$ & $\begin{array}{l}\text { offline channel } \\
\text { only }\end{array}$ & online & offline & $\begin{array}{l}\text { across bi- } \\
\text { weeks with } \\
\text { cat. purch. }\end{array}$ & $\begin{array}{l}\text { across bi- } \\
\text { weeks with } \\
\text { cat. purch. \& } \\
\text { MC trans. }\end{array}$ \\
\hline Fresh Meat & 421 & $1215(33.27 \%)$ & $429(11.75 \%)$ & $2008(54.98 \%)$ & 3.90 & 7.66 & .27 & .41 \\
\hline Charcuterie & 572 & $2147(25.96 \%)$ & $754(9.12 \%)$ & $5371(64.93 \%)$ & 5.07 & 13.14 & .20 & .34 \\
\hline Fresh Fish & 385 & $1102(28.77 \%)$ & $55(1.44 \%)$ & $2673(69.79 \%)$ & 3.01 & 9.81 & .05 & .08 \\
\hline Fruit & 567 & $2020(26.82 \%)$ & $726(9.64 \%)$ & $4786(63.54 \%)$ & 4.84 & 12.00 & .23 & .39 \\
\hline Vegetables & 640 & $2572(24.42 \%)$ & $879(8.35 \%)$ & $7081(67.23 \%)$ & 5.39 & 15.08 & .17 & .27 \\
\hline Bakery pastry & 581 & $2112(25.62 \%)$ & $561(6.81 \%)$ & $5569(67.57 \%)$ & 4.60 & 13.22 & .12 & .20 \\
\hline Fat & 520 & $1728(30.62 \%)$ & $718(12.72 \%)$ & $3197(56.65 \%)$ & 4.70 & 9.47 & .33 & .54 \\
\hline Cheese & 624 & $2427(26.14 \%)$ & $1076(11.59 \%)$ & $5782(62.27 \%)$ & 5.61 & 13.16 & .26 & .42 \\
\hline Milk & 580 & $2169(34.60 \%)$ & $1011(16.13 \%)$ & $3088(49.27 \%)$ & 5.48 & 9.06 & .37 & .64 \\
\hline Yoghurt & 590 & $2299(25.96 \%)$ & $916(10.34 \%)$ & $5641(63.70 \%)$ & 5.45 & 13.46 & .23 & .37 \\
\hline Canned fruit \& veg. & 525 & $1716(35.41 \%)$ & $670(13.83 \%)$ & $2460(50.76 \%)$ & 4.54 & 7.95 & .41 & .62 \\
\hline Condiments \& sauces & 484 & $1411(32.90 \%)$ & $481(11.21 \%)$ & $2397(55.89 \%)$ & 3.91 & 7.87 & .30 & .46 \\
\hline Breakfast cereals & 362 & $1064(32.86 \%)$ & $349(10.78 \%)$ & $1825(56.36 \%)$ & 3.90 & 7.98 & .37 & .59 \\
\hline Biscuits & 515 & $1758(29.42 \%)$ & $634(10.61 \%)$ & $3583(59.97 \%)$ & 4.64 & 10.37 & .26 & .43 \\
\hline Pastes \& rice & 495 & $1443(34.03 \%)$ & $535(12.62 \%)$ & $2262(53.35 \%)$ & 4.00 & 7.48 & .37 & .56 \\
\hline Chocolate & 437 & $1283(29.86 \%)$ & $398(9.26 \%)$ & $2616(60.88 \%)$ & 3.85 & 8.92 & .23 & .37 \\
\hline Hot beverages & 505 & $1794(32.90 \%)$ & $759(13.92 \%)$ & $2900(53.18 \%)$ & 5.06 & 9.30 & .37 & .55 \\
\hline Water & 603 & $2413(39.80 \%)$ & $1231(20.30 \%)$ & $2419(39.90 \%)$ & 6.04 & 8.01 & .56 & .84 \\
\hline Juice & 408 & $1258(35.92 \%)$ & $411(11.74 \%)$ & $1833(52.34 \%)$ & 4.09 & 7.58 & .42 & .65 \\
\hline Soft drinks & 504 & $1768(34.00 \%)$ & $813(15.63 \%)$ & $2619(50.37 \%)$ & 5.12 & 8.70 & .49 & .73 \\
\hline Pet food & 237 & $900(34.19 \%)$ & $455(17.29 \%)$ & $1277(48.52 \%)$ & 5.72 & 9.19 & .47 & .67 \\
\hline General body care & 511 & $1608(31.63 \%)$ & $535(10.53 \%)$ & $2940(57.84 \%)$ & 4.19 & 8.90 & .28 & .48 \\
\hline Washing products & 538 & $1713(39.13 \%)$ & $687(15.69 \%)$ & $1978(45.18 \%)$ & 4.46 & 6.86 & .54 & .77 \\
\hline Toilet paper & 522 & $1707(38.00 \%)$ & $627(13.96 \%)$ & $2158(48.04 \%)$ & 4.47 & 7.40 & .49 & .73 \\
\hline Cleaning products & 578 & $1940(30.56 \%)$ & $686(10.81 \%)$ & $3722(58.63 \%)$ & 4.54 & 9.80 & .38 & .60 \\
\hline $\begin{array}{l}\text { Average (across } 25 \\
\text { cat.) }\end{array}$ & & $31.71 \%$ & $11.84 \%$ & $56.45 \%$ & 4.66 & 9.69 & .33 & .51 \\
\hline
\end{tabular}


Table 2: Variable Notation \& Description

\begin{tabular}{|c|c|c|c|}
\hline Notation & Name & Description & Formula \\
\hline$S C S_{i t}^{c}$ & $\begin{array}{l}\text { Share in category } \\
\text { spending of consumer } \mathrm{i} \\
\text { for category c in period } \mathrm{t}\end{array}$ & 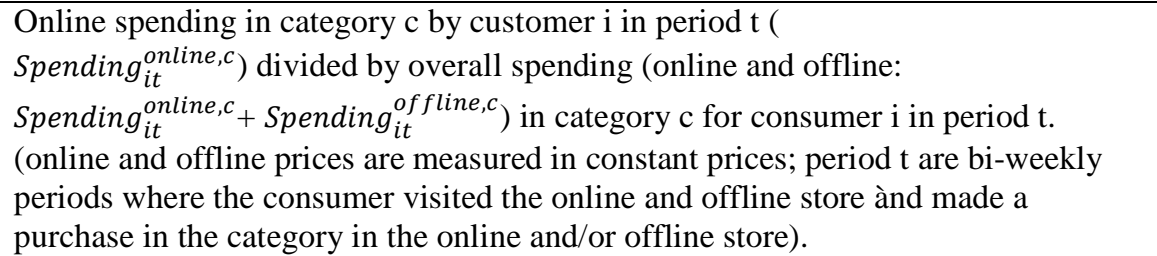 & $\begin{array}{l}\text { SCS }_{i t}^{C}= \\
\frac{\text { Spending }_{i t}^{\text {online }, c}}{\left(\text { spending }_{i t}^{\text {online }, c}+\text { Spending }_{i t}^{\text {offline,c }}\right)}\end{array}$ \\
\hline$S T S_{i t}$ & $\begin{array}{l}\text { Share in total spending } \\
\text { of consumer } \mathrm{i} \text { in period } \mathrm{t}\end{array}$ & $\begin{array}{l}\text { Online spending across all categories by customer } \mathrm{i} \text { in period } \mathrm{t}\left(\text { Spending } \text { online }_{\text {on }} \text { ) }\right. \\
\text { divided by the overall grocery spending (online and offline: } \\
\text { Spending } \text { online }_{\text {of }}+\text { Spending }_{i t}^{\text {offline }} \text { ) for consumer i in period } \mathrm{t} \text {. }\end{array}$ & 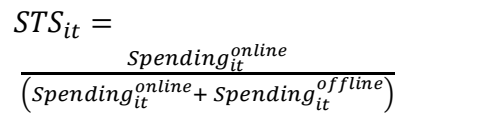 \\
\hline$A s s^{c}$ & $\begin{array}{l}\text { Assortment difference } \\
\text { for category c }\end{array}$ & $\begin{array}{l}\text { Assortment difference ratio (number of SKUs in category } \mathrm{c} \text { in the online store } \\
\text { divided by the number of SKUs in category } \mathrm{c} \text { in the offline store). }\end{array}$ & Ass $^{c}=\frac{\text { Ass }^{\text {online }, c}}{\text { Ass }^{\text {offline }, c}}$ \\
\hline Price $^{c}$ & $\begin{array}{l}\text { Price difference for } \\
\text { category c }\end{array}$ & $\begin{array}{l}\text { The unit price difference (difference between online and offline average unit prices } \\
\text { computed over a common set of category products, i.e., the set of products that are } \\
\text { available in both channels). }\end{array}$ & $\begin{array}{l}\text { Price }^{c}=\text { Price } \\
\quad-\text { Price }^{\text {offline }, c} \\
\end{array}$ \\
\hline $\operatorname{Promo}_{t}^{c}$ & $\begin{array}{l}\text { Online share in } \\
\text { promotion intensity for }\end{array}$ & $\begin{array}{l}\text { 'Share-of-voice' based variable, measured as the share in overall category } \\
\text { promotions of the online store (number of SKUs on promotion in category c in the }\end{array}$ & $\begin{array}{l}\operatorname{Promo}_{t}^{c}= \\
\operatorname{NrPromo}_{t}^{\text {online,c }}\end{array}$ \\
\hline & category $\mathrm{c}$ in period $\mathrm{t}$ & $\begin{array}{l}\text { online store in period } t \text {, divided by the number of SKUs on promotion in category c } \\
\text { in the online and offline store combined in period } t \text {; equal to } 0 \text { in case there were no } \\
\text { promotions in the category). }\end{array}$ & $\overline{\operatorname{NrPromo}_{t}^{\text {online }, c}+\operatorname{NrPromo}_{t}^{\text {of fline }, \mathrm{c}}}$ \\
\hline$I S S^{c}$ & $\begin{array}{l}\text { In-store stimuli dummy } \\
\text { variable for category c }\end{array}$ & $\begin{array}{l}\text { Indicator variable equal to } 1 \text { if sensitivity towards in-store stimuli is high for } \\
\text { category c, } 0 \text { elsewhere. }\end{array}$ & \\
\hline Sens $^{c}$ & $\begin{array}{l}\text { Sensory dummy variable } \\
\text { for category c }\end{array}$ & Indicator variable equal to 1 if category $\mathrm{c}$ is a sensory category, 0 elsewhere. & \\
\hline $\begin{array}{l}\text { Bulky } \\
\text { _Heavy }\end{array}$ & $\begin{array}{l}\text { Bulky/heavy dummy } \\
\text { variable for category c }\end{array}$ & $\begin{array}{l}\text { Indicator variable equal to } 1 \text { if category } \mathrm{c} \text { is a bulky or heavy item category, } 0 \\
\text { elsewhere. }\end{array}$ & \\
\hline $\operatorname{Exp}_{i t}^{c}$ & $\begin{array}{l}\text { Online buying } \\
\text { experience of consumer i } \\
\text { for category c in period } t\end{array}$ & $\begin{array}{l}\text { Weighted sum of previous online purchases in category c for consumer } \mathrm{i} \text { in period } \mathrm{t} \\
\left.\left(b_{i, t-1}^{c}\right) \text {, with weights equal to } \lambda \text { (between } 0-1\right) \text { and based on all the previous } \\
\text { periods (s=1, } \ldots, \mathrm{t}-1) \text { to capture fading effects, and } \operatorname{Exp}_{i 1}^{c} \text { as starting value based on } \\
\text { an initialization period of } 26 \text { bi-weeks (we used } \lambda=.7 \text { and checked the results' } \\
\text { sensitivity via robustness checks). }\end{array}$ & $\begin{array}{l}\operatorname{Exp}_{i t}^{c}=\lambda * \operatorname{Exp}_{i, t-1}^{c}+\lambda * b_{i, t-1}^{c}= \\
\sum_{s=1}^{s=t-1} \lambda^{t-s} * b_{i, t-1}^{c}+\lambda^{t-1} * \operatorname{Exp}_{i, 1}^{c}\end{array}$ \\
\hline Usage $_{i}^{c}$ & $\begin{array}{l}\text { Online usage level of } \\
\text { consumer i for category c }\end{array}$ & $\begin{array}{l}\text { Indicator variable of whether consumer } i \text { is a heavy user of category } \mathrm{c} \text { based on the } \\
\text { estimation period. }\end{array}$ & \\
\hline
\end{tabular}


Table 3: Classification of 25 categories

\begin{tabular}{|c|c|c|c|c|c|}
\hline Category & $\begin{array}{l}\text { Assortment } \\
\text { reduction } \\
\left(_{\text {Low/High) }}{ }^{\mathrm{a}}\right.\end{array}$ & $\begin{array}{l}\text { Price } \\
\text { difference } \\
\text { (Low/High) }^{\mathrm{b}}\end{array}$ & $\begin{array}{l}\text { Impulse } \\
\text { (Yes/No) }\end{array}$ & $\begin{array}{l}\text { Sensory } \\
\text { (Yes/No) }\end{array}$ & $\begin{array}{l}\text { Bulky/heavy } \\
\text { (Yes/No) }\end{array}$ \\
\hline Fresh Meat & High & High & No & Yes & No \\
\hline Charcuterie & High & High & No & Yes & No \\
\hline Fresh Fish & High & High & No & Yes & No \\
\hline Fruit & Low & Low & No & Yes & No \\
\hline Vegetables & High & Low & No & Yes & No \\
\hline Bakery pastry & High & Low & Yes & Yes & No \\
\hline Fat & Low & Low & No & No & No \\
\hline Cheese & High & High & No & Yes & No \\
\hline Milk & Low & Low & No & No & No \\
\hline Yoghurt & High & Low & No & No & No \\
\hline Canned fruit \& vegetables & High & High & No & No & No \\
\hline Condiments \& sauces & Low & High & No & No & No \\
\hline Breakfast cereals & Low & High & No & No & No \\
\hline Biscuits & High & High & Yes & No & No \\
\hline Pastes \& rice & High & High & No & No & No \\
\hline Chocolate & Low & High & Yes & No & No \\
\hline Hot beverages & Low & High & No & No & No \\
\hline Water & Low & Low & No & No & Yes \\
\hline Juice & Low & Low & No & No & No \\
\hline Soft drinks & Low & Low & No & No & Yes \\
\hline Pet food & Low & High & No & No & No \\
\hline General body care & High & High & No & No & No \\
\hline Washing products & Low & Low & No & No & No \\
\hline Toilet paper & High & Low & No & No & Yes \\
\hline Cleaning products & Low & High & No & No & No \\
\hline
\end{tabular}

${ }^{\mathrm{a}}$ The low and high assortment reduction cover the range of .461-.614 and .060-.459, respectively.

${ }^{a}$ The low and high price difference cover the range of .000-.289 and .320-2.000, respectively. 
Table 4: Model Estimation Results ${ }^{\mathrm{a}}$

\begin{tabular}{|c|c|c|c|c|c|}
\hline \multirow[t]{2}{*}{ Variables } & \multirow{2}{*}{$\begin{array}{c}\text { Homog. } \\
\text { model }\end{array}$} & \multicolumn{4}{|c|}{ Four-segment model } \\
\hline & & Seg. 1 & Seg. 2 & Seg. 3 & Seg. 4 \\
\hline \multicolumn{6}{|c|}{ PANEL A: Parameter coefficients } \\
\hline Constant $\left(\gamma_{01}\right)$ & $-5.654 * * *$ & $-5.518 * * *$ & $-3.877 * *$ & $-4.796 * *$ & $-6.914 * * *$ \\
\hline Latent factor $\left(\gamma_{02}\right)$ & $-1.048 * * *$ & $.772 * * *$ & $.670 * * *$ & $-1.144 * * *$ & $.573 * * *$ \\
\hline Share in total spending $\left(\gamma_{1}\right)$ & $9.680 * * *$ & $7.901 * * *$ & $6.862 * * *$ & $10.316^{* * *}$ & $10.955 * * *$ \\
\hline Experience $\left(\gamma_{2}\right)$ & $2.232 * * *$ & $1.846^{* * *}$ & $10.535 * * *$ & $3.441 * * *$ & $.711 * *$ \\
\hline Usage level $\left(\gamma_{3}\right)$ & $-.239 * * *$ & -.046 & -.054 & $-.389 * * *$ & $-.298 * * *$ \\
\hline \multicolumn{6}{|l|}{ Acquisition utility (marketing mix) } \\
\hline Assortment $\left(\delta_{10}\right)$ & $3.297 *$ & $6.710^{*}$ & -.887 & -3.136 & 5.782 \\
\hline Assortment $*$ Experience $\left(\delta_{11}\right)$ & $1.006 * * *$ & .738 & $5.439 *$ & $1.729 * *$ & -.159 \\
\hline Price $\left(\delta_{20}\right)$ & $-.270 * *$ & -.074 & $-1.564 * * *$ & .084 & -.087 \\
\hline Price * Experience $\left(\delta_{21}\right)$ & $.463 * * *$ & $1.041 * * *$ & -.953 & -.247 & $1.050 * * *$ \\
\hline Promotion $\left(\delta_{30}\right)$ & $.270 *$ & $.737 * *$ & -.031 & .306 & .096 \\
\hline Promotion $*$ Experience $\left(\delta_{31}\right)$ & $-.365 * *$ & -.635 & .621 & -.276 & -.388 \\
\hline In-store stimuli $\left(\delta_{40}\right)$ & $-1.445^{* * *}$ & $-.606 * *$ & $-1.468 * * *$ & $-1.124 * * *$ & $-1.881 * *$ \\
\hline In-store stimuli $*$ Experience $\left(\delta_{41}\right)$ & .155 & $-.650 *$ & $-3.092 * * *$ & -.078 & $.367 *$ \\
\hline \multicolumn{6}{|c|}{ Transaction utility (category characteristics) } \\
\hline Sensory $\left(\delta_{50}\right)$ & $-2.717 * * *$ & $-4.527 * * *$ & $-3.379 * * *$ & $-1.695 *$ & -.364 \\
\hline Sensory $*$ Experience $\left(\delta_{51}\right)$ & $.964 * * *$ & $2.054 * * *$ & -1.253 & $-.519 * *$ & $.470 * *$ \\
\hline Bulky/Heavy $\left(\delta_{60}\right)$ & $2.867 * * *$ & $2.118 * * *$ & $5.212 * * *$ & $4.156 * * *$ & $.681 * *$ \\
\hline Bulky/Heavy * Experience $\left(\delta_{61}\right)$ & $-.855^{* * *}$ & $-.848 * * *$ & $-9.724 * * *$ & $-.762 * * *$ & $.552 * * *$ \\
\hline Residual assortment $\left(\theta_{1}\right)$ & 2.023 & -.195 & 4.682 & $7.085^{*}$ & -.078 \\
\hline Residual price $\left(\theta_{2}\right)$ & $-.326^{* *}$ & -.194 & $1.569 * * *$ & $-.763 * *$ & $-1.316^{* * *}$ \\
\hline Segment membership $\left(\varphi_{\mathrm{s}}\right)$ & & $29 \%$ & $22 \%$ & $14 \%$ & $35 \%$ \\
\hline $\mathrm{BIC}$ & 256333.8 & & 253 & 28.3 & \\
\hline \multicolumn{6}{|c|}{ PANEL B: Segment characteristics } \\
\hline Average online buying exp first 4 bi-weeks & & .339 & .128 & .394 & .451 \\
\hline Average online buying exp last 6 bi-weeks & & .490 & .191 & .668 & .837 \\
\hline Change in average online buying exp & & .151 & .063 & .274 & .386 \\
\hline Total online spending amount $(€)$ & & 932.69 & 401.47 & 1041.25 & 1677.81 \\
\hline Total offline spending amount $(€)$ & & 1505.21 & 2825.98 & 3554.61 & 1718.19 \\
\hline Average online purchase share (\%) & & 72.64 & 46.01 & 42.16 & 78.83 \\
\hline
\end{tabular}

$\mathrm{a} *$ significant at $\mathrm{p}<.10 ; * *$ significant at $\mathrm{p}<.05 ; * * *$ significant at $\mathrm{p}<.01$. 
Figure 1: Conceptual framework \& Expected effects

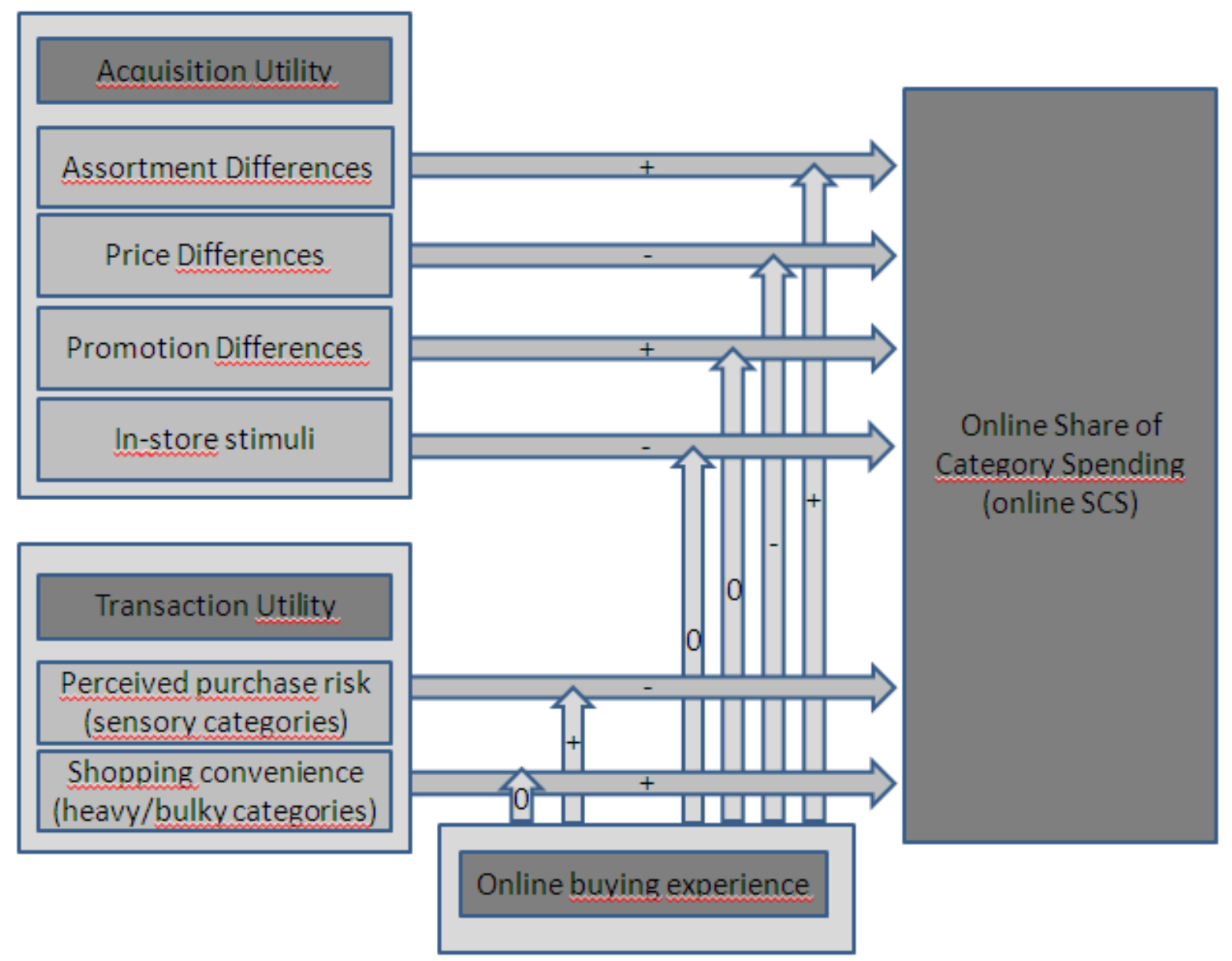


Figure 2: Model Goodness-of-Fit

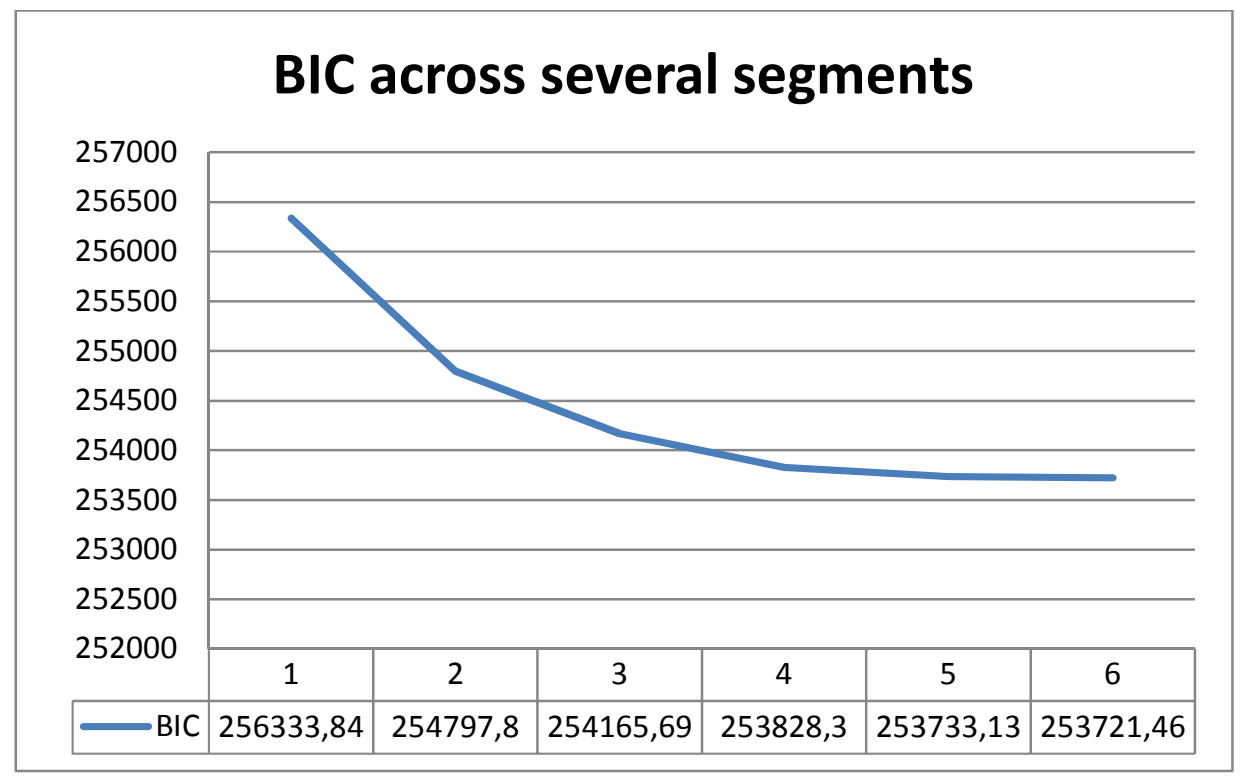




\section{Web Appendix A: Endogeneity correction}

An important aspect that we need to control for is potential endogeneity. When deciding on the online store's marketing mix, retail managers can take the expected impact on consumer buying behavior into account. The explanatory marketing variables can in that case be the result as well as the cause of variations in the dependent variable. For example, retailers may take into account that the need for variety is generally higher for hedonic than for functional categories, and for that reason offer a larger online assortment (reduce the online assortment less) for such hedonic categories. Similarly, channel differences in price can be smaller for categories where price sensitivity is expected to be high. We therefore expect that the endogeneity problem is especially important for the assortment and price variables because these are typically long-term strategic decisions. Promotions, on the other hand, are expected not to have an endogeneity problem because they are short-term decisions made independently from the other channel.

To control for the endogeneity problem of assortment and price variables, we follow a control function approach proposed by Wooldridge (2013). First, we include all exogenous variables of the main model (except interactions) and the instrumental variables in the control functions for assortment (A.1) and price differences (A.2):

(A.1) CFAss $^{c}=\sum_{n=1}^{N} \sigma_{n} X_{n}+\operatorname{Res}_{-} A s s^{c}$,

(A.2) CFPrice $^{c}=\sum_{n=1}^{N} \omega_{n} X_{n}+$ Res_Price $^{c}$, where $\mathrm{N}$ is the number of explanatory characteristics that are used to control for the endogenous nature of the assortment and price variables and $\mathrm{X}$ are the selected (exogenous and instrumental) variables. As instruments, we use characteristics that may influence retailers' management decisions of the marketing mix instruments, but that are not affected by our dependent variable. Based on the literature on assortment size and pricing/promotion decisions (Dhar et al. 2001; 
Van Trijp et al. 1996), we include a 'staple' dummy variable (high purchase frequency, high penetration) and a functional vs. hedonic dummy variable as instruments. Dhar et al. (2001) classify categories into high and low penetration (\% of households that purchase the category) and high and low frequency (average number of times per year that the category is purchased). We expect that retailers are less inclined to significantly reduce the online assortment or increase online prices for staple categories as these are categories where many consumers often purchase. Regarding the hedonic/functional nature of a category, we expect that managers are less likely to strongly reduce the assortment for categories where hedonic features (e.g., enjoyable to use) are more important than for categories where functional features (e.g., excellent performance) are more important. Hedonic categories tend to attract more variety-seeking behavior and therefore require larger assortments to satisfy variety needs. Prior literature has also shown that price sensitivity tends to be lower in hedonic categories, because the decision process is more emotional than rational oriented (Sethuraman 2003).

To operationalize the staple dummy variable, we use the same spirit as Dhar et al. (2001) and classify categories as staple when they are bought by a large $\%$ of households in the online plus offline channel, and when they are purchased a large number of times per year in the online plus offline channel. More particularly, we use a median split for penetration and frequency, resulting in a classification where fruit, vegetables, bakery, yoghurt among others are identified as staple (cf. Dhar et al. 2001). To operationalize the functional vs. hedonic dummy variable, we use expert assessments and check the validity of the classification by a limited survey with statements that were evaluated on a 7-point Likert scale.

In the second step, we retain the residuals of the control function models and use them to correct for the endogenous problem by including them in the main model as additional variables. 
The idea behind adding the residuals to the main model is to include a proxy variable that conditions on the part of the dependent variable that depends on the unobserved factors (Petrin and Train 2010). Hence:

$$
\begin{aligned}
& \text { (A.3) } V_{i t}^{c}=\left[\gamma_{0 i}+\gamma_{1} * \text { STS }_{i t}+\gamma_{2} * \operatorname{Exp}_{i t}^{c}+\gamma_{3} * \text { Usage }_{i}^{c}\right]+\left[\delta_{1} * \text { Ass }^{c}+\delta_{2} * \text { Price }^{c}+\delta_{3} *\right. \\
& \text { Promo } \left.^{c}+\delta_{4} * I S S^{c}\right]+\left[\delta_{5} * \text { Sens }^{c}+\delta_{6} * \text { Bulky_Heavy }^{c}\right]+\left[\theta_{1} * \text { Res_Ass }^{c}+\theta_{2} *\right. \\
& \text { Res_Price } \\
& \text { Re }] .
\end{aligned}
$$

where the residuals of the assortment $\left(\operatorname{Res}_{-} \mathrm{Ass}^{\mathrm{c}}\right)$ and price $\left(\right.$ Res_Price $\left.^{\mathrm{c}}\right)$ are included as additional variables. All the other variables and parameters are the same as discussed in Equation (3) of the main text.

Table A.1 gives on an overview of the estimation results of the control function models. In this discussion, we focus on the results of the two instruments. The fit indices are acceptable (adjusted $\mathrm{R}^{2}$ for assortment $=.546$ and for price $\left.=.301\right)$. We find that the staple dummy variable has a negative significant effect on assortment differences $\left(\sigma_{\text {staple }}=-.006 ; \mathrm{p}<.01\right)$ and price differences $\left(\omega_{\text {staple }}=-.312 ; \mathrm{p}<.01\right)$. Hence, retailers tend to offer a smaller online assortment and charge a lower online price premium for frequently and commonly purchased categories. The functional dummy variable has, in line with expectations, a negative effect on assortment differences $\left(\sigma_{\text {functional }}=-.008 ; \mathrm{p}<.01\right)$, and a negative effect on price differences $\left(\omega_{\text {functional }}=-.256\right.$; $\mathrm{p}<.01$ ). Hence, as expected, online price premiums are lower (higher) but online assortment reductions are larger (smaller) for functional (hedonic) products. 
Table A.1: Results of the control function models

\begin{tabular}{lcc}
\hline Variables & Assortment & Price \\
\hline Intercept & $.453^{* * *}$ & $.748^{* * *}$ \\
Share in total spending & $.008^{* * *}$ & $-.029 * * *$ \\
Experience & $.011^{* * *}$ & $-.033^{* * *}$ \\
Usage level & $-.003 * * *$ & $.009 * * *$ \\
Promotion & $.036^{* * *}$ & $-.045^{* * *}$ \\
In-store stimuli & $-.061^{* * *}$ & $.122^{* * *}$ \\
Sensory & $-.211^{* * *}$ & $-.092^{* * *}$ \\
Bulky/Heavy & $.055^{* * *}$ & $-.388^{* * *}$ \\
Staple (high penetration/high frequency) category & $-.006 * * *$ & $-.312^{* * *}$ \\
Functional (versus hedonic) category & $-.008^{* * *}$ & $-.256^{* * *}$ \\
$\mathrm{R}^{2}$ & .546 & .301 \\
\hline
\end{tabular}

* significant at $\mathrm{p}<.10 ; * *$ significant at $\mathrm{p}<.05 ; * * *$ significant at $\mathrm{p}<.01$. 


\section{Web Appendix B: Robustness Checks}

We conducted several robustness checks to verify the validity of our model and the consistency of our findings. We summarize them here.

Impact of sample selection criteria.

We re-estimated our model with less stringent selection criteria, i.e., using all observations where there was an online visit (irrespective of whether there also was an offline visit). Table B.1 reports the estimation results of the homogeneous model for both selections. It is clear that substantive results are almost identical, although the model with less stringent selection criteria results in higher parameter values for some variables, most likely to compensate for the boundary conditions (share of category spending automatically equal to 1 when there was no offline store visit in that week). When latent class estimation is used, this problem becomes even worse for some segments. We therefore decided to maintain the selection criteria that we discuss in our paper.

Including additional category characteristics or testing different variable operationalizations.

We included additional category-specific characteristics like a perishability variable on top of - or instead of - the sensory variable, a high ticket variable capturing possible higher perceived online purchase risks of expensive products, a separate variable for heavy and one for bulky categories. We also tested different operationalizations for the marketing mix differences (dummy rather than continuous variables to indicate large assortment reductions and high price premiums, a price variable based on markup percentages instead of price differences, or impulse ratings from the survey data instead of the dummy variable). We further tested nonlinear effects of category-specific online buying experience (captured by a quadratic function for Equation 4), used a general (not category-specific) experience variable and checked the sensitivity of the weight used to capture fading effects for the operationalization of the category-specific online 
buying experience (see also Table 2 in the manuscript). We also checked the robustness of the endogeneity correction by running a model with an endogeneity correction for the promotion variable, by splitting residuals (positive and negative) of the price and assortment correction, and by using other operationalizations of our instrumental variables. We found that the selected model and variable operationalizations outperform the alternative ones, both in terms of model fit and face validity of the estimates.

\section{Using a different time span.}

To test whether the categories' purchase frequency - and the choice of bi-weekly periods - influences the estimation results, we re-estimated the model using monthly data. While the results were quite robust for the homogeneous model, we found that the bi-weekly model specification outperforms the month-based heterogeneous model (similar goodness-of-fit, but much lower face validity of the results).

Using another model structure.

Instead of using one share of category spending model as we currently do, we also ran a two-stage model, where we modeled the category channel choice and spending decisions separately. We have added the results of the homogeneous model in Table B.2. The conclusions are very similar, yet less easy to grasp. Therefore, we decided to simplify the model, and to integrate the category channel choice and spending decisions into a single share of category spending model (with a dependent variable that can be equal to zero, one, or any value between these two boundaries). In addition to being more logic, the results are also more clear and straightforward to interpret. 
Table B.1: Impact of sample selection criteria

Parameter estimates of homogeneous model with (i) current sample selection, as described in the manuscript ('current') and (ii) less stringent sample selection, using all observations where there was an online visit (irrespective of whether there was an offline visit; 'online visit').

\begin{tabular}{|c|c|c|}
\hline \multirow[t]{2}{*}{ Variables } & \multicolumn{2}{|c|}{ Homogeneous model } \\
\hline & 'current' & 'online visit' \\
\hline Constant $\left(\gamma_{01}\right)$ & $-5.654 * * *$ & $65.614 * * *$ \\
\hline Latent factor $\left(\gamma_{02}\right)$ & $-1.048 * * *$ & $.752 * * *$ \\
\hline Share in total spending $\left(\gamma_{1}\right)$ & $9.680 * * *$ & $12.116^{* * *}$ \\
\hline Experience $\left(\gamma_{2}\right)$ & $2.232 * * *$ & $3.712 * * *$ \\
\hline Usage level $\left(\gamma_{3}\right)$ & $-.239 * * *$ & $-.719 * * *$ \\
\hline \multicolumn{3}{|l|}{ Acquisition utility (marketing mix) } \\
\hline$\overline{\operatorname{Assortment}\left(\delta_{10}\right)}$ & $3.297 *$ & $4.581 * * *$ \\
\hline Assortment $*$ Experience $\left(\delta_{11}\right)$ & $1.006 * * *$ & $-.977 * * *$ \\
\hline Price $\left(\delta_{20}\right)$ & $-.270 * *$ & $-.563 * * *$ \\
\hline Price $*$ Experience $\left(\delta_{21}\right)$ & $.463 * * *$ & $.435 * * *$ \\
\hline Promotion $\left(\delta_{30}\right)$ & $.270 *$ & $6.148 * * *$ \\
\hline Promotion $*$ Experience $\left(\delta_{31}\right)$ & $-.365 * *$ & $-.215^{* *}$ \\
\hline In-store stimuli $\left(\delta_{40}\right)$ & $-1.445 * * *$ & $-11.561 * * *$ \\
\hline In-store stimuli $*$ Experience $\left(\delta_{41}\right)$ & .155 & $.347 * * *$ \\
\hline \multicolumn{3}{|c|}{ Transaction utility (category characteristics) } \\
\hline Sensory $\left(\delta_{50}\right)$ & $-2.717 * * *$ & $-35.949 * * *$ \\
\hline Sensory $*$ Experience $\left(\delta_{51}\right)$ & $.964 * * *$ & $.848 * * *$ \\
\hline Bulky/Heavy $\left(\delta_{60}\right)$ & $2.867 * * *$ & $11.868 * * *$ \\
\hline Bulky/Heavy $*$ Experience $\left(\delta_{61}\right)$ & $-.855 * * *$ & $-.361 * * *$ \\
\hline Residual assortment $\left(\theta_{1}\right)$ & 2.023 & $-164.282 * * *$ \\
\hline Residual price $\left(\theta_{2}\right)$ & $-.326 * *$ & $3.662 * * *$ \\
\hline
\end{tabular}

$*$ significant at $\mathrm{p}<.10 ; * *$ significant at $\mathrm{p}<.05 ; * * *$ significant at $\mathrm{p}<.01$. 
Table B.2: Results of a two-stage homogeneous model

The two-stage model defines sub-models for (i) the decision to select the online channel to make a purchase in the category ('channel choice decision'), and (ii) the decision on how much to purchase of the category in the online store, given that the online channel is selected for buying the category ('share in category spending decision').

\begin{tabular}{|c|c|}
\hline Sub-model \& Variables & Parameter estimates \\
\hline \multicolumn{2}{|l|}{ CHANNEL CHOICE DECISION } \\
\hline Constant $\left(\alpha_{01}\right)$ & $1.3553 * *$ \\
\hline Latent factor $\left(\alpha_{02}\right)$ & $-.9182 * *$ \\
\hline Experience $\left(\alpha_{1}\right)$ & $.7105^{* *}$ \\
\hline Usage level $\left(\alpha_{2}\right)$ & $.1867 * *$ \\
\hline \multicolumn{2}{|l|}{ Acquisition utility (marketing mix) } \\
\hline$\overline{\text { Assortment }\left(\beta_{10}\right)}$ & .0893 \\
\hline Assortment $*$ Experience $\left(\beta_{11}\right)$ & $.3652 *$ \\
\hline Price $\left(\beta_{20}\right)$ & $-.4920 * *$ \\
\hline Price * Experience $\left(\beta_{21}\right)$ & .0750 \\
\hline Promotion $\left(\beta_{30}\right)$ & .0635 \\
\hline Promotion $*$ Experience $\left(\beta_{31}\right)$ & -.0041 \\
\hline In-store stimuli $\left(\beta_{40}\right)$ & $-.2938 * *$ \\
\hline In-store stimuli $*$ Experience $\left(\beta_{41}\right)$ & .0579 \\
\hline \multicolumn{2}{|c|}{ Transaction utility (category characteristics) } \\
\hline Sensory $\left(\beta_{50}\right)$ & $-.8209 * *$ \\
\hline Sensory * Experience $\left(\beta_{51}\right)$ & $.4959 * *$ \\
\hline Bulky/Heavy $\left(\beta_{60}\right)$ & $.5182 * *$ \\
\hline Bulky/Heavy * Experience $\left(\beta_{61}\right)$ & -.0656 \\
\hline Residual assortment $\left(\theta_{1}\right)$ & $1.3780 * *$ \\
\hline Residual price $\left(\theta_{2}\right)$ & $.3071 * *$ \\
\hline \multicolumn{2}{|c|}{ SHARE IN CATEGORY SPENDING DECISION } \\
\hline Constant $\left(\gamma_{01}\right)$ & $.0991 * *$ \\
\hline Latent factor $\left(\gamma_{02}\right)$ & $-.1240 * *$ \\
\hline Share in total spending $\left(\gamma_{1}\right)$ & $.3771 * *$ \\
\hline Experience $\left(\gamma_{2}\right)$ & $.0353 * *$ \\
\hline Usage level $\left(\gamma_{3}\right)$ & $-.0744 * *$ \\
\hline \multicolumn{2}{|l|}{ Acquisition utility (marketing mix) } \\
\hline Assortment $\left(\delta_{10}\right)$ & $.0794 * *$ \\
\hline Assortment $*$ Experience $\left(\delta_{11}\right)$ & .0056 \\
\hline Price $\left(\delta_{20}\right)$ & $.0888 * *$ \\
\hline Price $*$ Experience $\left(\delta_{21}\right)$ & $-.0182 *$ \\
\hline Promotion $\left(\delta_{30}\right)$ & -.0025 \\
\hline Promotion * Experience $\left(\delta_{31}\right)$ & -.0147 \\
\hline In-store stimuli $\left(\delta_{40}\right)$ & $-.0746^{* *}$ \\
\hline In-store stimuli $*$ Experience $\left(\delta_{41}\right)$ & .0073 \\
\hline \multicolumn{2}{|c|}{ Transaction utility (category characteristics) } \\
\hline Sensory $\left(\delta_{50}\right)$ & $-.0850 * *$ \\
\hline Sensory * Experience $\left(\delta_{51}\right)$ & $.0237 * *$ \\
\hline Bulky/Heavy $\left(\delta_{60}\right)$ & $.0818 * *$ \\
\hline Bulky/Heavy * Experience $\left(\delta_{61}\right)$ & .0051 \\
\hline Residual assortment $\left(\mu_{1}\right)$ & $.1452 * *$ \\
\hline Residual price $\left(\mu_{2}\right)$ & $-.0389 * *$ \\
\hline Mill's ratio $(\lambda)$ & $-.1203 * *$ \\
\hline $\mathrm{R}^{2}(\mathrm{CC} / \mathrm{SCS})$ & $.4722 / .3174$ \\
\hline $\mathrm{BIC}(\mathrm{CC} / \mathrm{SCS})$ & 44739 / 54433 \\
\hline
\end{tabular}

* significant at $\mathrm{p}<.10 ; * *$ significant at $\mathrm{p}<.05 ; * * *$ significant at $\mathrm{p}<.01$. 